\title{
The Global Sustainability Project and the LLNL China Energy Systems Model
}

\author{
Alan Lamont \\ Jeffery Stewart \\ Woodrow Clark \\ N. Wait Harris
}

February 1999

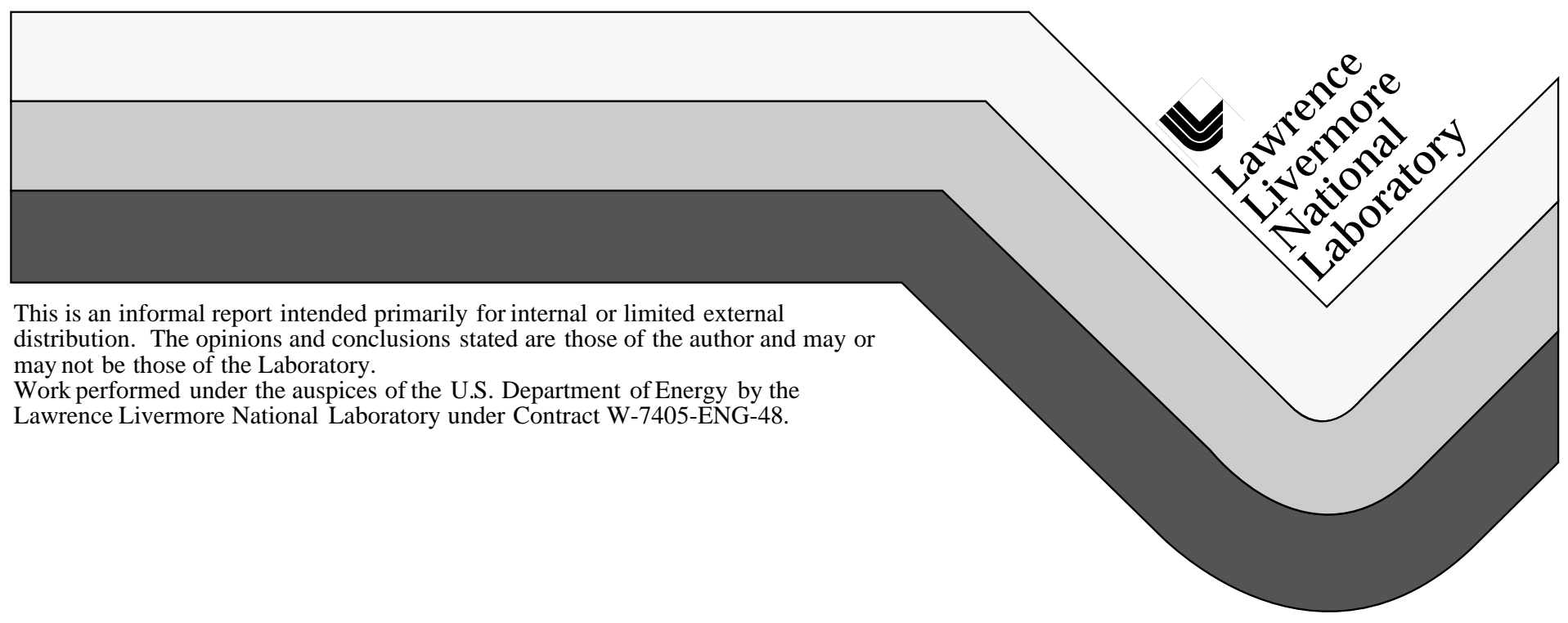




\section{DISCLAIMER}

This document was prepared as an account of work sponsored by an agency of the United States Government. Neither the United States Government nor the University of California nor any of their employees, makes any warranty, express or implied, or assumes any legal liability or responsibility for the accuracy, completeness, or usefulness of any information, apparatus, product, or process disclosed, or represents that its use would not infringe privately owned rights. Reference herein to any specific commercial product, process, or service by trade name, trademark, manufacturer, or otherwise, does not necessarily constitute or imply its endorsement, recommendation, or favoring by the United States Government or the University of California. The views and opinions of authors expressed herein do not necessarily state or reflect those of the United States Government or the University of California, and shall not be used for advertising or product endorsement purposes.

This report has been reproduced directly from the best available copy.

Available to DOE and DOE contractors from the Office of Scientific and Technical Information P.O. Box 62, Oak Ridge, TN 37831

Prices available from (423) 576-8401

Available to the public from the National Technical Information Service

U.S. Department of Commerce 5285 Port Royal Rd., Springfield, VA 22161 


\section{The Global Sustainability Project and the LLNL China Energy Systems Model}

Alan Lamont, Jeffery Stewart, Woodrow Clark, N. Wait Harris

February 1999 



\section{Table of Contents}

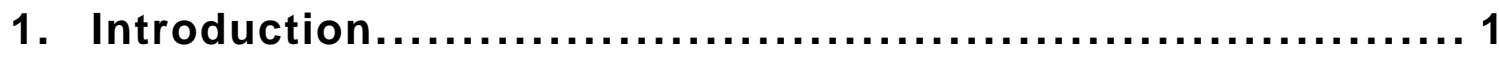

1.1 Background of the Global Sustainability project ............................................ 1

1.2 Summary of project work this year ............................................................... 1

1.3 Overview of the remainder of the report .................................................... 2

2. Modeling approach and overview of the META•Net modeling

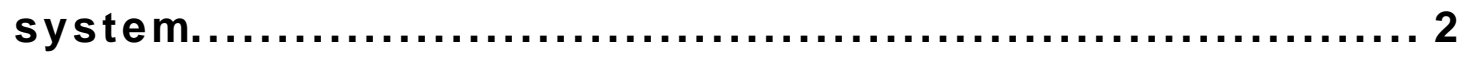

2.1 Computation of prices, quantities and economic equilibrium ........................... 3

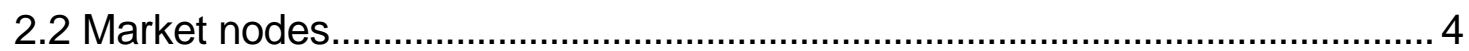

2.3 Relationship to optimization models ............................................................ 6

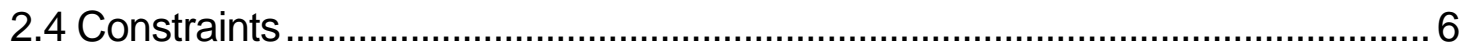

3. Software development for META•Net ...................6 6

4. Overview of the China energy system model...............7

4.1 Applications of the model and analytical support by the project to other

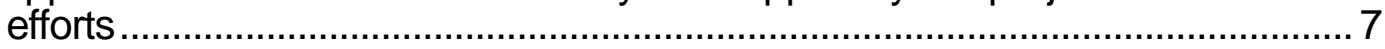

4.2 Issues the model is designed to address ……........................................... 8

5. Structure and Parameters of the China model............. 9

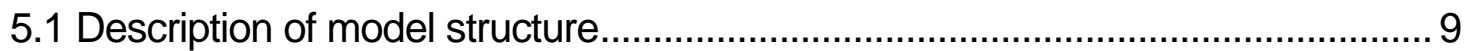

5.1.1 Primary resources and energy production.........................................10

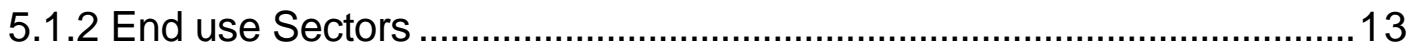

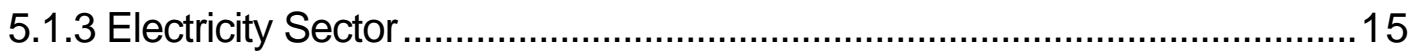

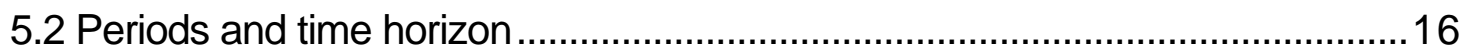


6. Base Case Results and Model Validation $\ldots \ldots \ldots \ldots \ldots \ldots \ldots$

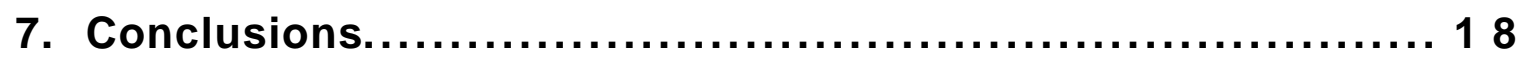

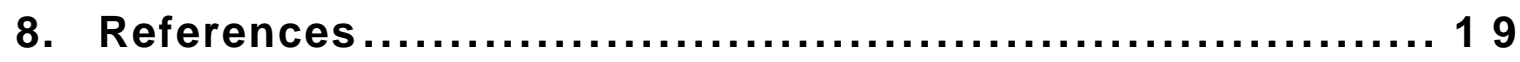

Appendix A: Derivation of input-output coefficients in industrial sector ........................................... 20

Appendix B: Model input data.............................. 20

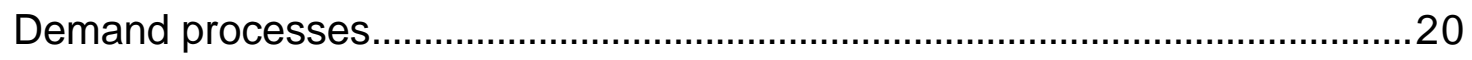

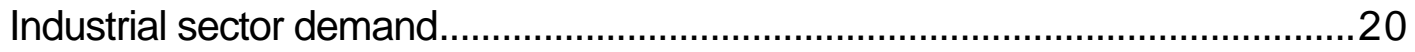

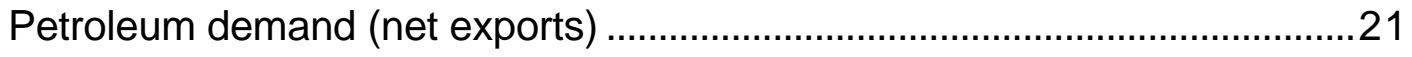

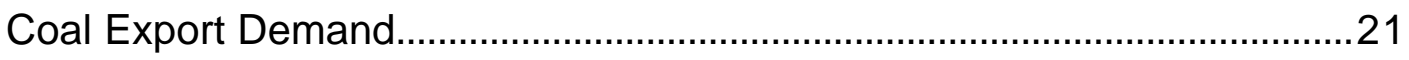

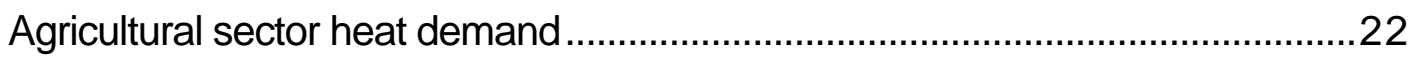

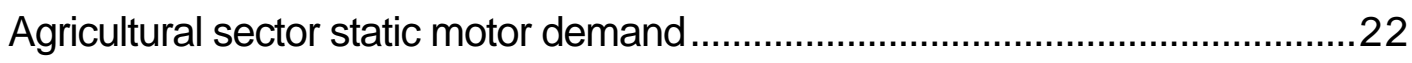

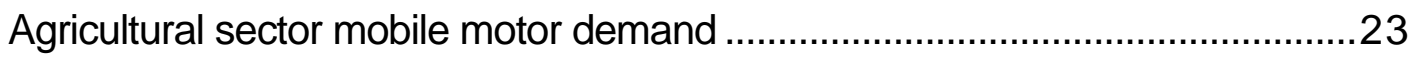

Commercial sector other electric demand....................................................23

Commercial sector heat demand ...............................................................24

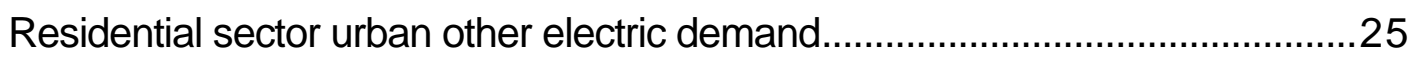

Residential sector rural heating and cooking demand.....................................25

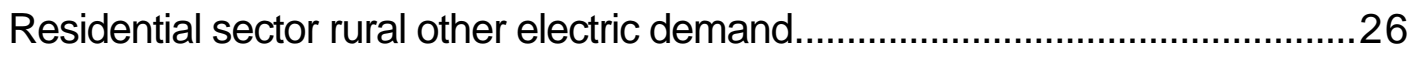

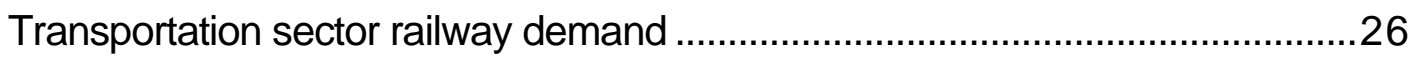

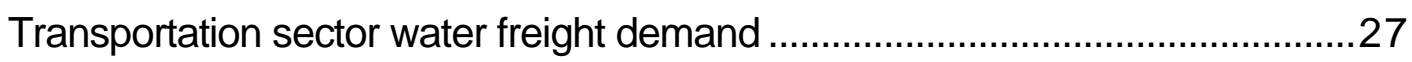

Transportation sector highway freight demand ..............................................27

Transportation sector highway passenger demand ........................................27

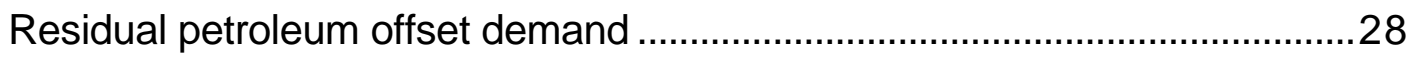

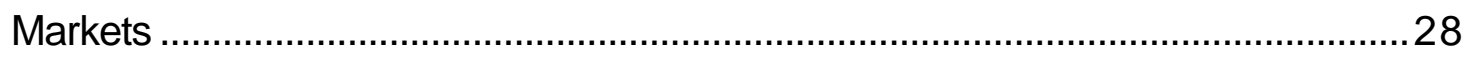

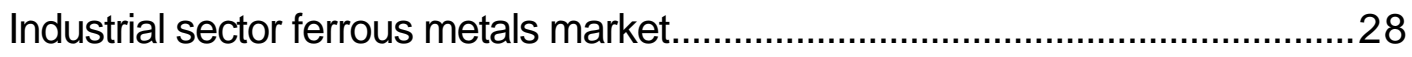

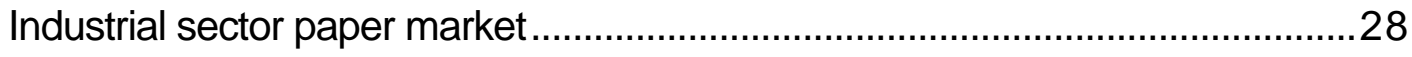

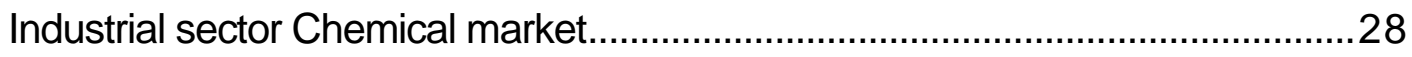

Industrial sector Building Material market.........................................................29

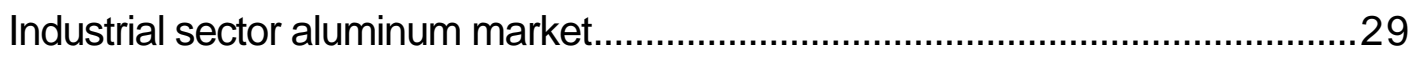

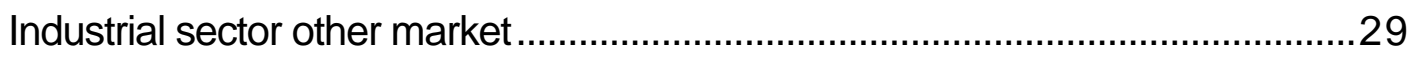

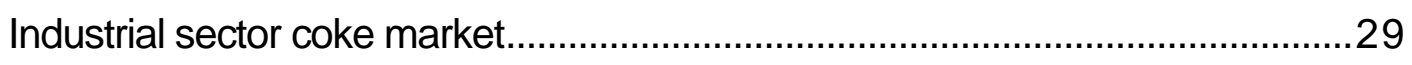




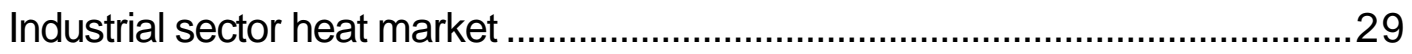

Industrial sector petroleum fuel market .......................................................29

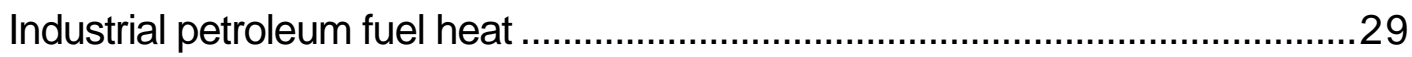

Industrial sector electric market ................................................................29

Agricultural sector static motor market ............................................................29

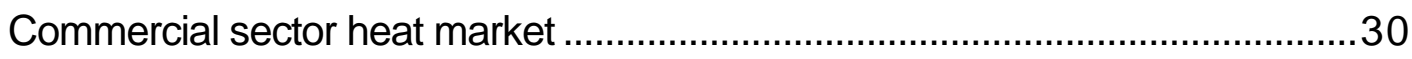

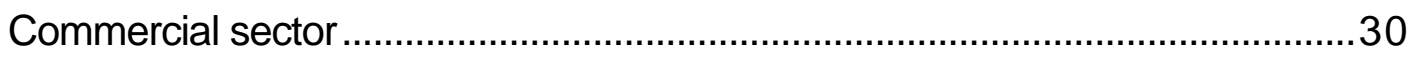

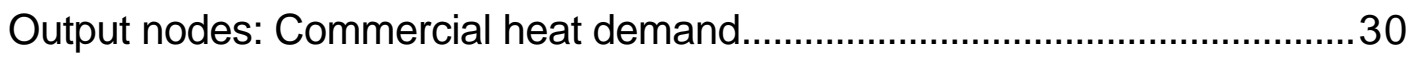

urban gas market.

Residential sector urban heat market …........................................................30

Residential sector urban cogeneration heat market ...........................................30

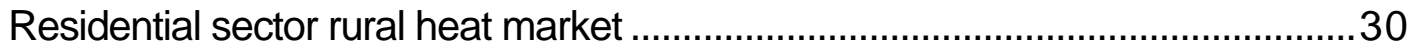

Transportation sector railway market ..........................................................30

Transportation sector petroleum market ......................................................30

Petroleum product market .........................................................................

Petroleum sector crude market …...............................................................

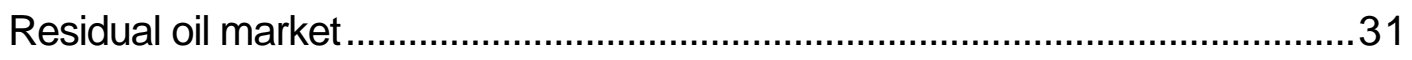

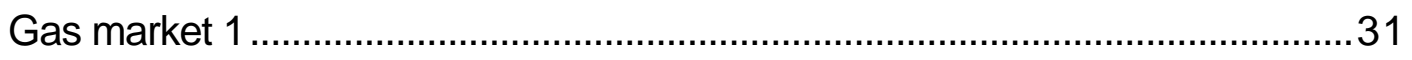

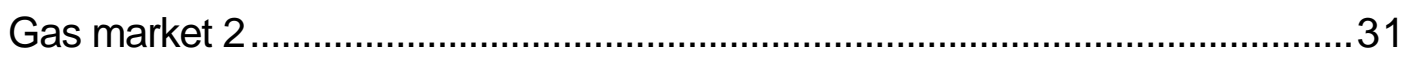

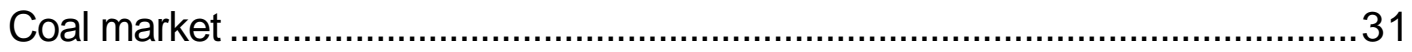

Electric market "summer" ............................................................................31

Electric market .....................................................................................

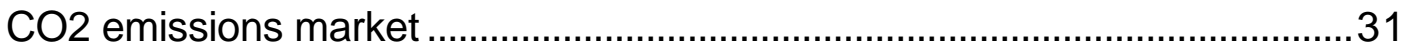

Sulfur emissions market.........................................................................

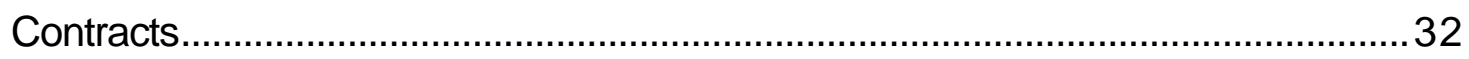

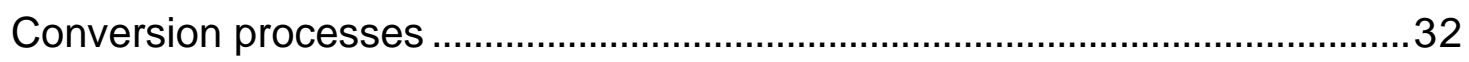

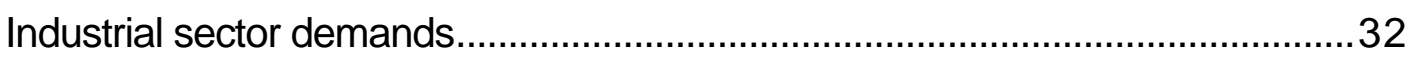

Old Ferrous metals Technology ...................................................................

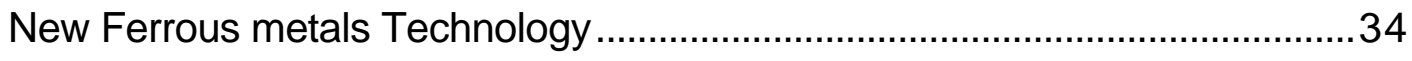

Old Paper Technology................................................................................

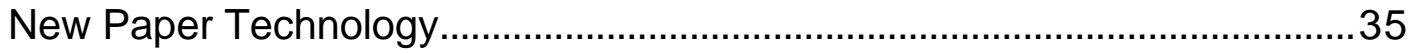

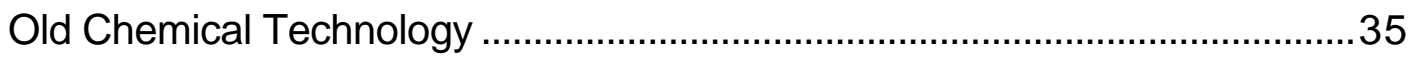

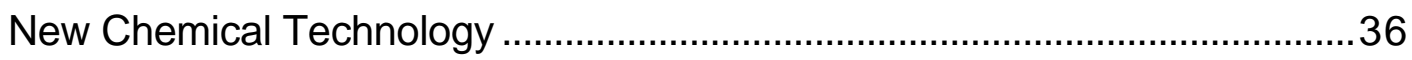

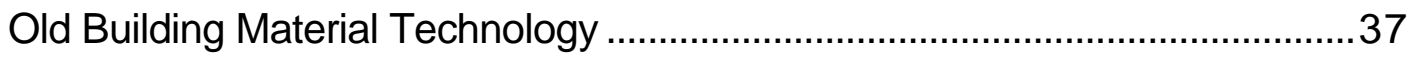

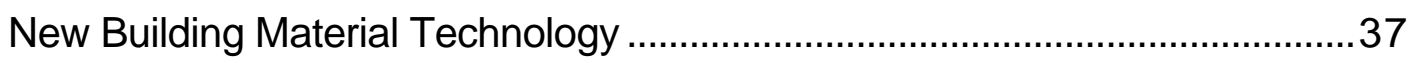




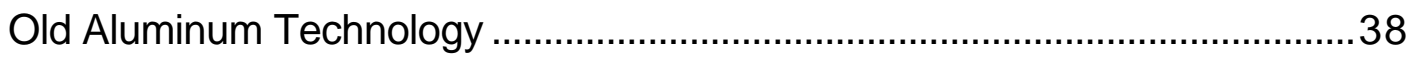

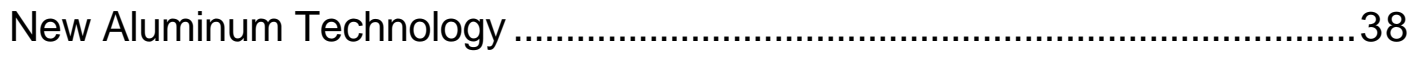

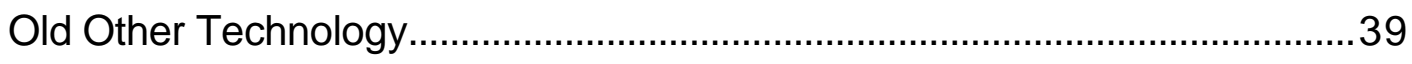

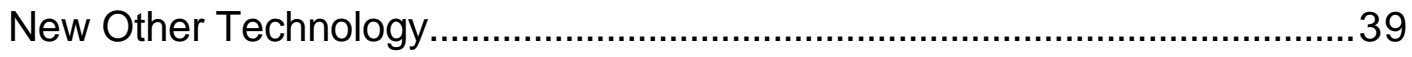

Industrial sector petroleum fuel heat ............................................................ 40

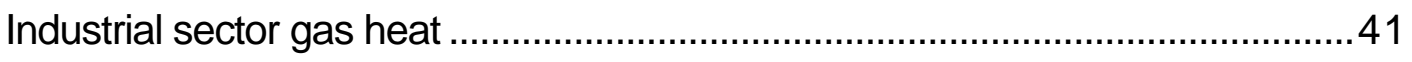

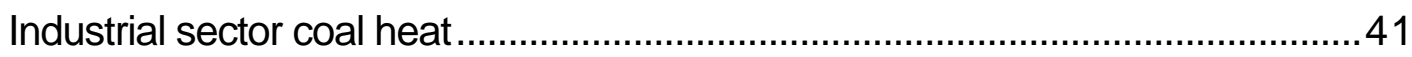

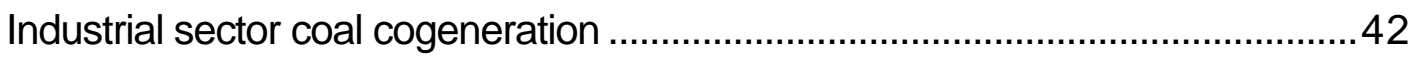

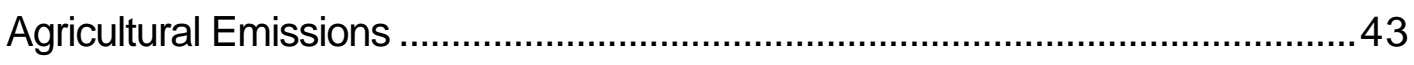

Agricultural sector static petroleum motor.......................................................

Agricultural sector static electric motor ......................................................... 44

Agricultural sector mobile petroleum motor ................................................. 44

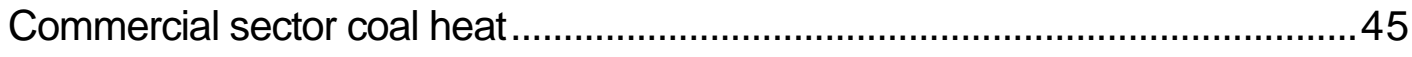

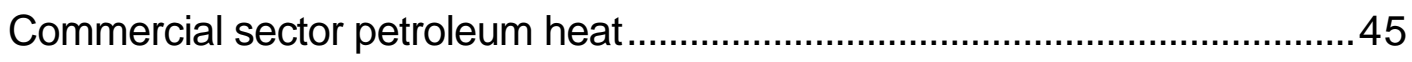

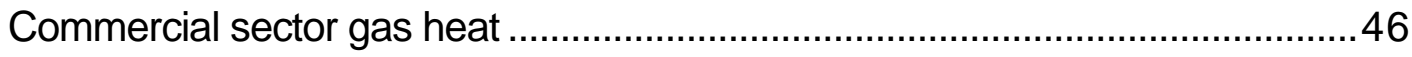

Urban gas distribution (Commercial and Residential sector)............................46

Residential sector urban district coal heat distribution .....................................47

Residential sector urban coal heat cogeneration.............................................48

Residential sector urban heat boiler (Coal District Heat)..................................48

Residential sector urban gas heat ............................................................... 49

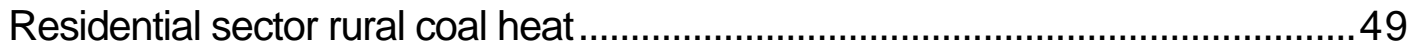

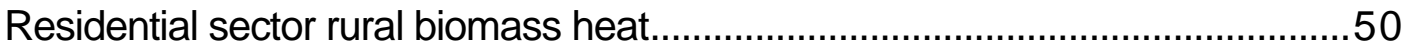

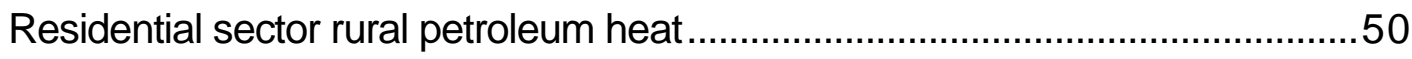

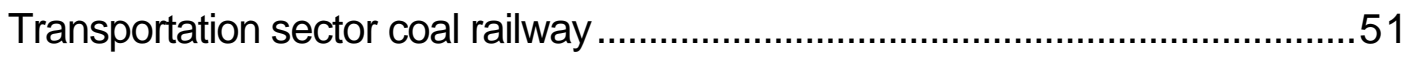

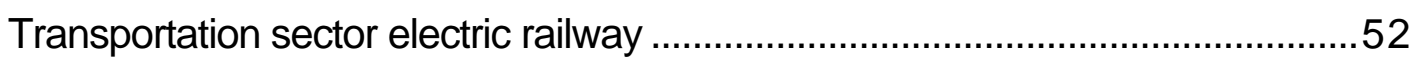

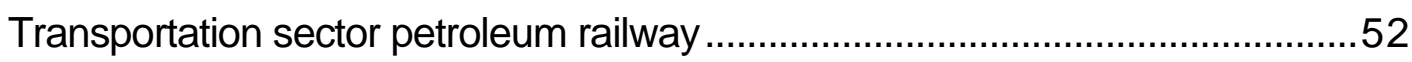

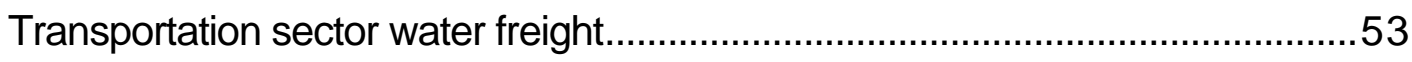

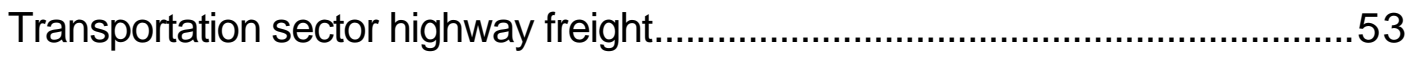

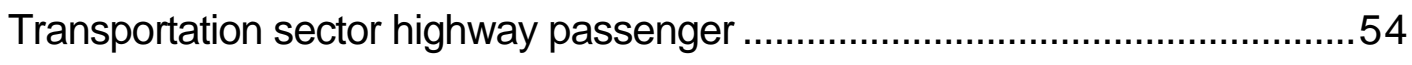

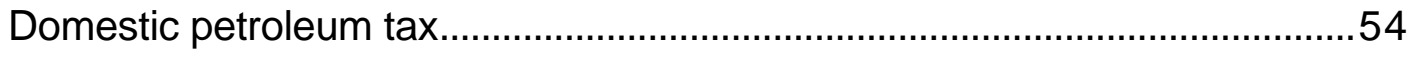

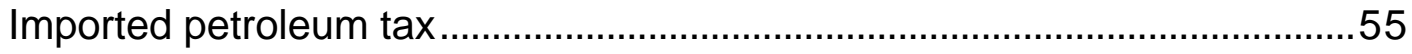

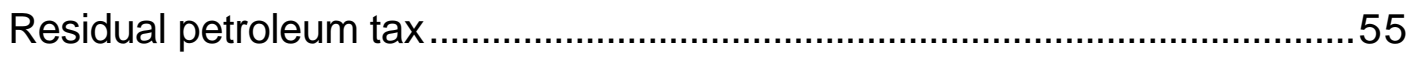

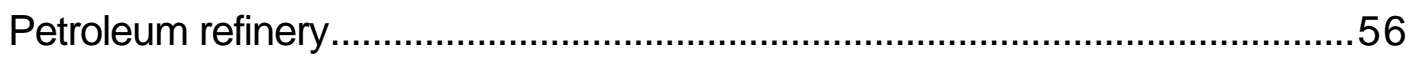

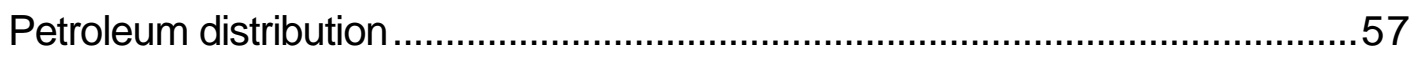

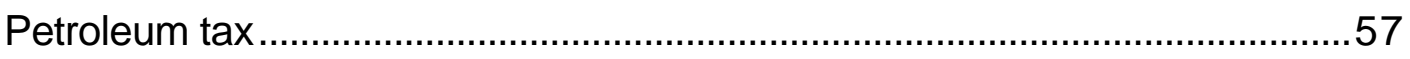




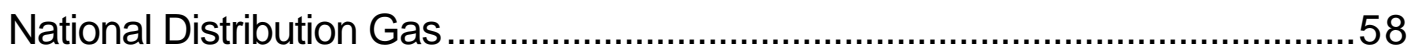

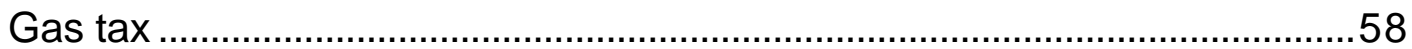

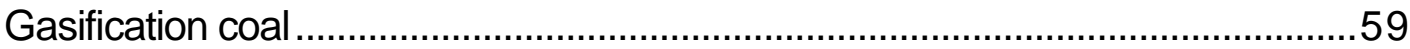

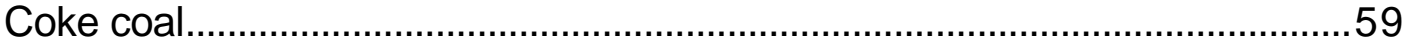

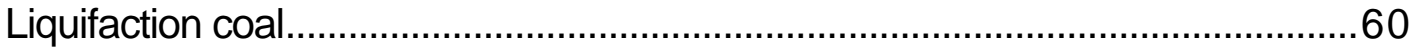

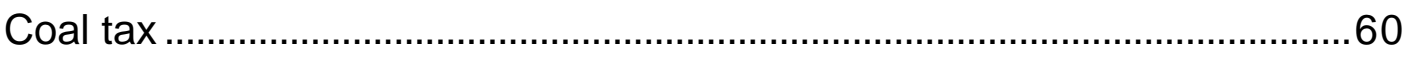

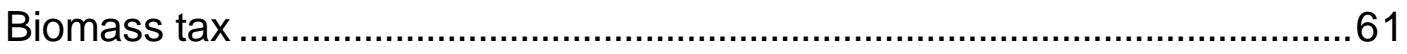

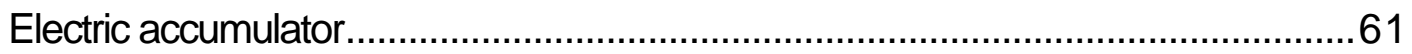

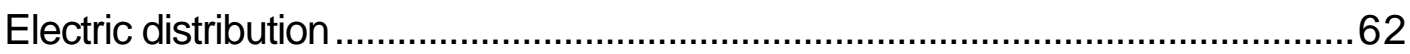

Oil Combined Cycle Elect...........................................................................62

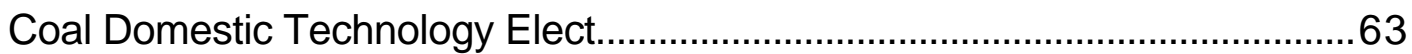

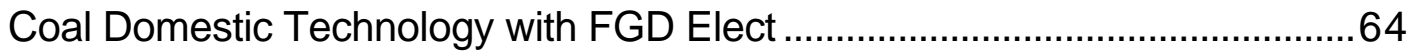

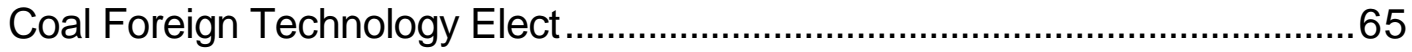

Coal Fluidized Bed Elect ........................................................................

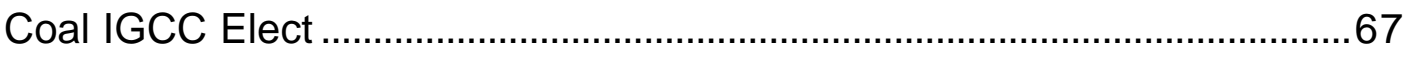

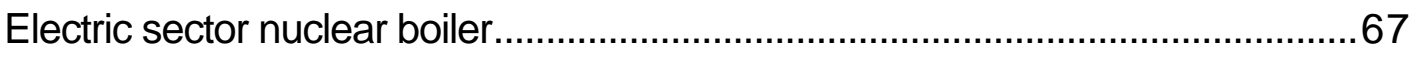

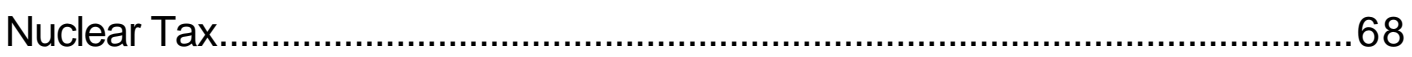

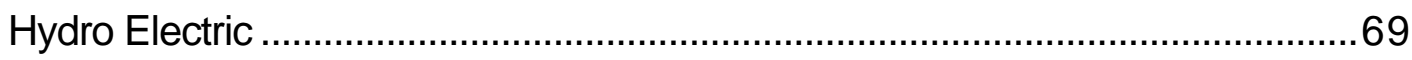

Hydro tax

Electric sector wind ................................................................................

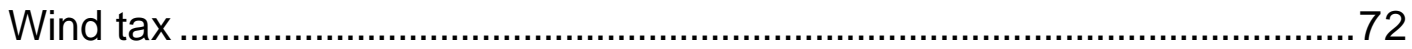

Sulfur emissions tax...............................................................................

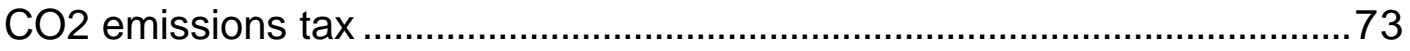

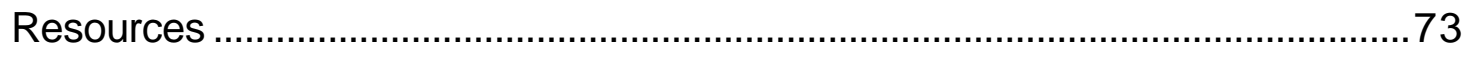

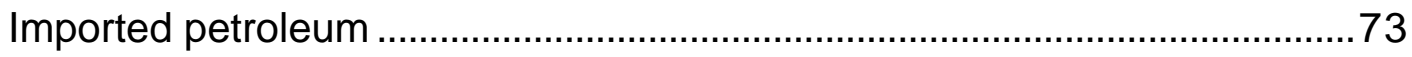

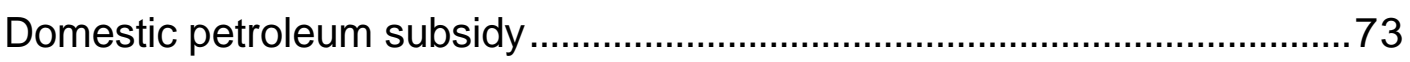

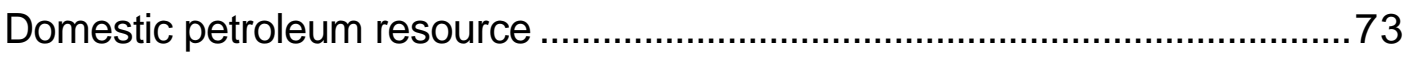

Residual petroleum resource.......................................................................

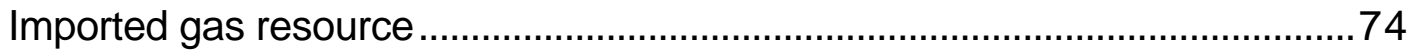

Domestic gas resource ........................................................................

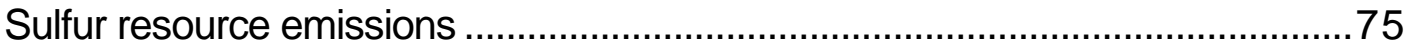

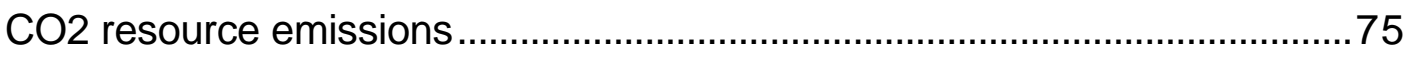

Domestic coal resource .......................................................................

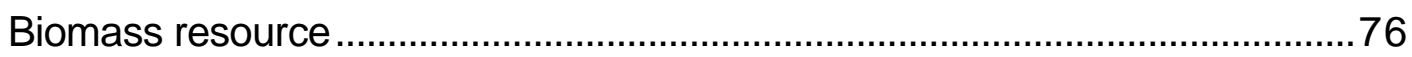

Nuclear electric resource .................................................................... 


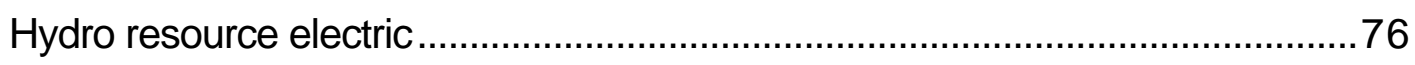

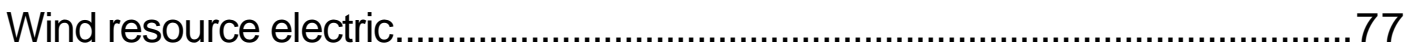

Appendix C: References for model parameters.............77

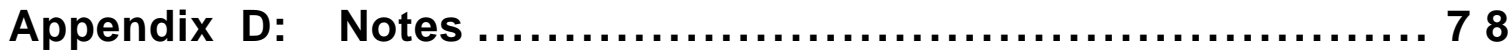

Appendix E: Derivation of growth rates $\ldots \ldots \ldots \ldots \ldots \ldots \ldots \ldots 79$ 


\section{Global Sustainability Project and LLNL China Energy Systems Model}

\section{Introduction}

\subsection{Background of the Global Sustainability project}

The sustainability of our modern way of life is becoming a major concern of both our domestic and international policy. The Rio conference on the environment and the recent Kyoto conference on global climate change are two indications of the importance of solving global environmental problem. Energy is a key component in global sustainability since obtaining and using it has major environmental effects.

If our energy systems are to be sustainable in the long run, they must be structured using technologies that have a minimal impact on our environment and resources. At the same time, they must meet practical economic requirements: they must be reasonably economical, they must meet the needs of society and they must be tailored to the resources that are available in a particular region or country. Because economic considerations and government policies both determine the development of the energy system, economic and systems modeling can help us better understand ways that new technologies and policies can be used to obtain a more sustainable system. The Global Sustainability Project has developed both economic modeling software and models to help us better understand these issues and has applied them to the analysis of energy and environmental problems in China. In the past year, the models and data developed by the project have been used to support other projects investigating the interaction of technologies and the environment.

\subsection{Summary of project work this year}

The project this year has focused on software development to improve our modeling tools and on the refinement and application of the China Energy System model. 
The major thrust of the software development has been improvements in the META•Net economic software system. We have modified its solution algorithm to improve speed and accuracy of the solutions and to make it compatible with the SuperCode modeling system. It is planned to eventually merge the two systems to take advantage of the faster, more flexible solution algorithms of SuperCode.

The China Energy system model has been extended somewhat and its parameters have been documented (they are included as an appendix to this report). As is discussed below, the model has been used this year in support of several analytic efforts assisted by this project.

\subsection{Overview of the remainder of the report}

The rest of the report discusses the modeling work that has been done this year. We first describe the economic modeling approach and the META-Net economic modeling system. A short description of the improvements made this year in META.Net is included. We then discuss the China Energy Systems model. The body of the report generally describes the model and each of its sectors. The studies that have been supported by this project are described. The Appendix, presents the documentation of the current model parameters. These describe the parameter values and the approaches used for estimating them.

\section{Modeling approach and overview of the META-Net modeling system}

This model is developed using the META.Net modeling system developed at LLNL (Lamont 1994). Under this approach, an economic system is represented as a network of interconnected nodes. The nodes represent economic processes such as end-use demand, conversion technologies, resources, and markets. The links pass information about quantities demanded and prices. Figure 1 shows a simple network for illustration.

META.Net is a modeling system that allows the user to build models based on this representation. It includes a library of node types and allows the user to build a model by simply specifying the 
nodes and their links. This approach has the advantage that it is easy to build and modify models. The node models can also be readily extended to model additional types of economic behavior.

The model is typically set up to compute a price quantity equilibrium over multiple period-the China model uses ten five-year periods. Over the model horizon, the model computes price trajectories, quantities, addition and retirement of capital stocks, and exhaustion of resources.

\subsection{Computation of prices, quantities and economic equilibrium}

To solve the model, we compute a price-quantity equilibrium through a sequence of iterations passing quantities demanded down from the end-use nodes and prices up from the resource nodes. At the start of an iteration, demands are generated at the end-use nodes. These are passed down the network. At market nodes the total market demand is allocated to the suppliers based on their relative prices (this is discussed in greater depth later). The conversion node represent fixed coefficient production processes. Based on the inputoutput coefficients, they compute the quantity of each input that that are required to produce the output required of them.

The quantities demanded eventually reach the resource nodes. At this point, the model begins to compute prices and send them back up through the network. Resource nodes contain resource curves that provide the marginal price required to produce the quantity demanded as a function of the total resource that has been exploited up to that period. The conversion nodes receive the prices for each input. Based on the prices of inputs, their I-O coefficients, capital costs, operating costs, and unit availability, the conversion nodes compute the price required in order that the owner of the process will receive a target rate of return on capital investments. The market nodes compute a quantity weighted average price for the market based and pass that on up. When the prices are received by the end-use nodes, a new quantity demanded is computed using a demand curve. These quantities are passed down to start a new iteration. 
Figure 1: Simple illustrative model network

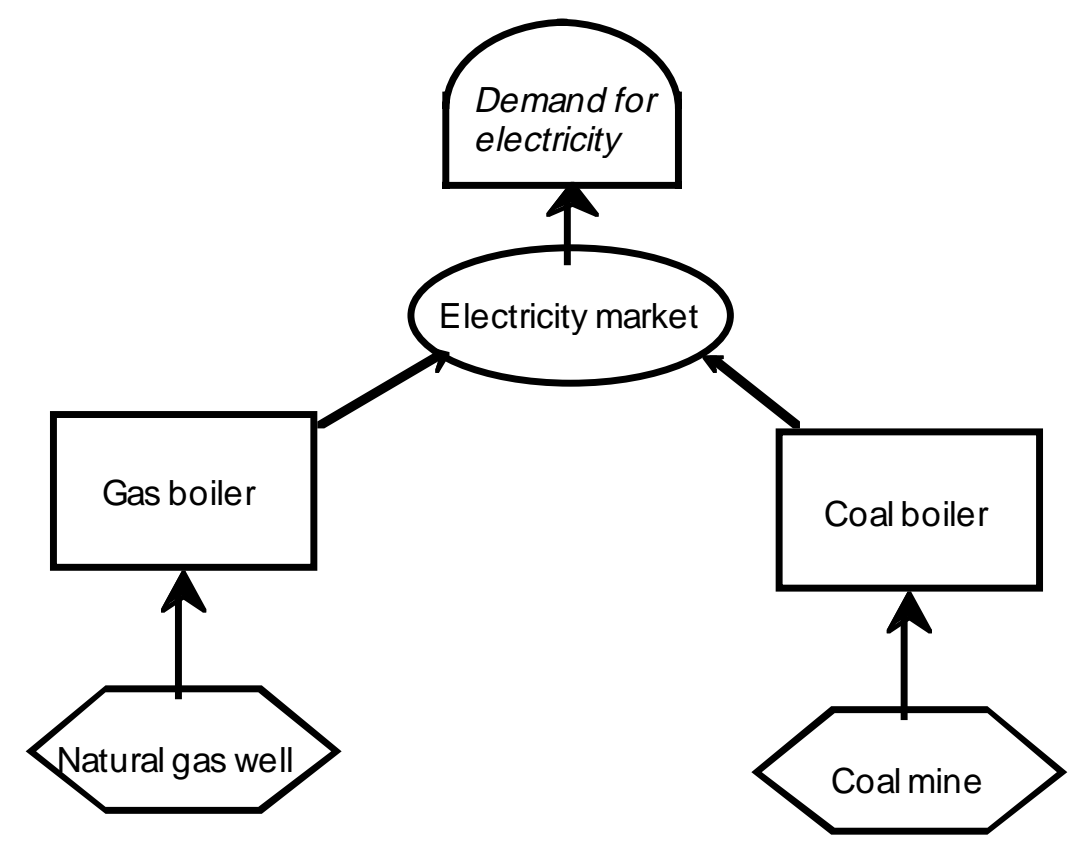

\subsection{Market nodes}

The market nodes compute the allocation of market demand to the market's suppliers based on their prices. Under this approach, the lowest price supplier does not receive the entire demand. Rather he receives a fraction of the demand based on the difference between his price and the prices of other suppliers. Such allocations are frequently done using a logistic function. However, in this case we use somewhat different approach developed by Boyd, et al.

This approach notes that the price on a single supply link to a market in the model actually represents a range of prices. These suppliers will typically have a distribution of costs (or prices that they must charge) and the price they actually charge may vary from instance to instance. Further, there can be a range of other costs that will change the effective price to a buyer. These might include transportation costs not represented in the model or other financing costs. The price for a supply link computed by the model represents the average price of all the suppliers on that link. Given that there is a distribution of prices, there will be instances when purchasing from a supplier on Link $A$ is less expensive than purchasing from suppliers on Link $B$, even if, on the average, the suppliers on Link $A$ are more expensive. 
Based on this approach, the fraction of the market that suppliers on link $A$ receive is computed as the fraction of instances where it is cheaper than the suppliers on another link. Heuristically, we can say that the more the two price distributions overlap, the more equal the market shares will be. When there are just two supply links to a market, we can write the equation for the fraction of the market going to supplier $A$ as:

Fract $_{\mathrm{A}}=\int_{0}^{\infty} f_{A}\left(p_{A}\right) \bullet F_{B}\left(p_{A}\right) \cdot d p_{A}$

where

$\mathrm{f}_{\mathrm{A}}\left(\mathrm{p}_{\mathrm{A}}\right)=$ The probability density distribution over the effective prices for suppliers on link A

$F_{B}\left(p_{A}\right)=$ The probability that the effective prices for all suppliers on link $B$ will be greater than $p_{A}$.

If we assume that the distribution of prices follows a Weibull distribution, then there is a simple equation for market share based on the average prices and a single parameter called the "market price sensitivity parameter". The larger the value of the parameter the more sensitive the market is to prices. That is in a very sensitive market, a supplier with a price just slightly higher than a competitor will receive a small market share. This occurs since a large value of price sensitivity implies a very narrow distribution of prices. Thus there are very few instances where the price distributions overlap. The market price sensitivity parameter is a direct function of the coefficient of variation (COV) ${ }^{1}$ of the price distributions.

The market share curves produced by this approach are similar in shape to those produced by a logistic market share function. However, using this formulation we can relate the market price sensitivity parameter directly to assumptions about the variability of prices in the market. In the sections below we will assume different values of the coefficient of variation to explore its impact on the results.

1 The coefficient of variation (COV) of a probability distribution is defined as (standard deviation)/mean 


\subsection{Relationship to optimization models}

There is a close relationship between economic equilibrium and cost minimization. A META.Net model can be set up to approximate a cost minimization solution. If the market nodes are set to be highly sensitive, they will allocate the demands to suppliers so as to approximately equalize their marginal costs. This minimizes the total cost of meeting the demand in the market. Overall this procedure will approximately minimize the total cost of meeting the demands.

\subsection{Constraints}

Both quantity and price constraints can be added to any of the links in the model. These operate by raising the prices sent to market nodes to ensure that the allocations meet the constraints. Based on the results from a model run, the shadow prices of the constraints can be estimated

\section{Software development for META•Net}

Tool development this year has focused on the META.Net economic modeling system. META.Net is a system for building models of economic systems and solving them for a price-quantity equilibrium over time.

Last year, the project worked with both the SuperCode modeling systems and the META.Net economic modeling system. SuperCode is a constrained optimization system that has been designed to work with other models. It is planned to eventually connect the two systems so that the more efficient solvers in SuperCode can be applied to META.Net. However, in the past, the META.Net algorithm worked by controlling quantities, whereas to connect the two systems, it is preferable to allow SuperCode to control prices in META.Net.

This year a number of improvements were made. The development effort for META-Net was leveraged with resources from one other project since improvements benefited both efforts. The major changes that have been made are:

Rewriting the solution algorithm so that it can seek a solution either by adjusting quantities or by adjusting prices. In the past the solution has worked by adjusting quantities only. Although this is usually effective, 
it essentially requires that constraints be implemented using barrier functions. It also is incompatible with the approach used by SuperCode.

Implementing constraints through derivatives. Previously, constraints were implemented through barrier functions-when a constraint is violated a very high price is generated forcing the solution back to the feasible region. However, this is often inefficient since the algorithm has no guidance about the amount by which the solution should be adjusted in order to meet the constraints. Introducing derivatives provides this guidance. The solution algorithm has been modified so that each node computes the derivative of the quantity of each input that it demands with respect to the price of that input. These are calculated analytically in each node and passed through the network. At points where constraints are implemented, the derivative information allows a node to better estimate the amount by which its price must be changed so as to meet the constraint.

\section{Overview of the China energy system model}

A major component of our analytic work has been the development and application of a model of the Chinese energy system. This is particularly urgent since China will soon be the world's largest emitter of carbon dioxide and other pollutants such as sulfur and particulates. From the Chinese point of view, the energy system will be largely coal based since that is the most abundant energy resource in China. However, the sulfur and particulate emissions cause extensive health, industrial, and agricultural damage. These emissions are the immediate targets of government policies and efforts to introduce new technologies. The China model can help find the most effective suites of new technologies and policies to deal with these.

\subsection{Applications of the model and analytical support by the project to other efforts}

We have applied the model, either directly through this project or in support of other projects, to understanding the reductions in emissions that can occur due to the introduction of new energy and industrial technologies. 
The first application examined the impact of improved industrial technologies on sulfur emissions in China. Chinese industries use energy very inefficiently (the amount of energy per unit output can be from two to five times that in the US or Europe). Consequently, improvements in industrial efficiency can be one method of reducing emissions of all types. The China model was used in a project with the Environmental Protections Division to explore the magnitude of emissions reductions that might be achieved by policies that encourage the introduction of modern industrial practices. The results indicate that emissions reductions achieved by even a moderate introduction of modern technologies can moderate the growth of sulfur emissions for about 25 years. Eventually, as China's economy grows and the industrial sector is converted to the new technologies, the growth rate in emissions increases. However, this indicates that one of the most effective emissions control policies will be financing and development of modern industrial facilities.

A second analysis, which was done in conjunction with the Office of Fossil Energy, focused on controlling emissions in the ChongQin region. This will investigate the feasibility and benefits of bringing natural gas and coal gasification technologies to the region. A modified version of the China model was developed to provide illustrative results that introducing these technologies might have on both the emissions and the energy mix in the ChongQin region. Our results, while preliminary, indicate that significant development of coal gasification may be needed

During the past year, Professor Toshihiko Nakata of Tohoku University in Japan was visiting LLNL to study modeling of energy systems. During his stay, he developed a model of the Japanese energy system using the META•Net modeling system and based on data which he obtained from Japan and data developed here at LLNL. $\mathrm{He}$ is using the model to evaluate strategies that Japan might use to reduce its carbon emissions in accordance with the Kyoto Protocol. The results of this work were presented at the annual meeting of the International Society of Energy Economists (Nakata, et al).

\subsection{Issues the model is designed to address}

The China model has been structured to assist in evaluating the efficacy of new technologies in reducing the costs and environmental 
impacts of energy production and use in China. As such, it is intended to project the changes in environmental emissions and prices that would arise as a technology is deployed throughout the economy.

However, in evaluating the impact of technologies, we must also investigate the extent to which a technology might be deployed and the effects of policies that are intended to encourage the deployment of technologies (not necessary specific technologies, but also classes of technologies that would help ameliorate a given problem). Thus, the China model is a also designed to evaluate the market penetration of technologies under market forces. It includes provisions to model a range of policy actions including taxes, subsidies, and constraints.

In its current form the model does not address more complex policy arrangements such as emissions trading (This has been done in earlier version of the META.Net modeling system [Lamont 1996]).

The modeling system is a partial equilibrium model of the energy sector. It does include some interactions with the rest of the economy through price sensitive demands for energy services. However, it assumes that capital is readily available and that the basic structure of energy demands is not greatly changed by policies or other events.

\section{Structure and Parameters of the China model}

This section provides an overview of the structure of the model and the approach that was taken to modeling each major

\subsection{Description of model structure}

The model represents the major features of the energy system in China. The sectors in the model have been selected to cover all of the major energy production, transformation and end-use activities in the economy. All significant uses of energy are covered, although they may be aggregated with others. Some, such as natural gas heating, have been included although they are not particularly significant today since they may become more important under some policies in the future. The system is represented as a single region with a single sector for each of the major energy producing and consuming activities. Figure 2 shows the basic structure of the model. 


\subsubsection{Primary resources and energy production}

The primary energy sources of coal, petroleum, natural gas, biomass, nuclear, wind, and hydro power are represented in the model. Each is represented as a homogeneous commodity in this version of the model. The sections below describe the basic approach taken in representing and modeling each area.

\subsubsection{Coal}

This version of the model uses a single grade of coal intended to represent average Chinese steam coal. The model sets the price of the coal at the average mine mouth price in the initial model year. The coal is distributed through a single distribution channel having a cost approximately equal to the average distribution cost in China. The resulting cost of coal to users is of average coal costs across China. Of course, there is a distribution of actual delivered prices of coal across China. This an important fact wherever coal competes with other fuels in the model. The fact of the price distribution is approximately accounted for by the market share functions in the markets where competition occurs. 
Figure 2: The structure of the China energy system model

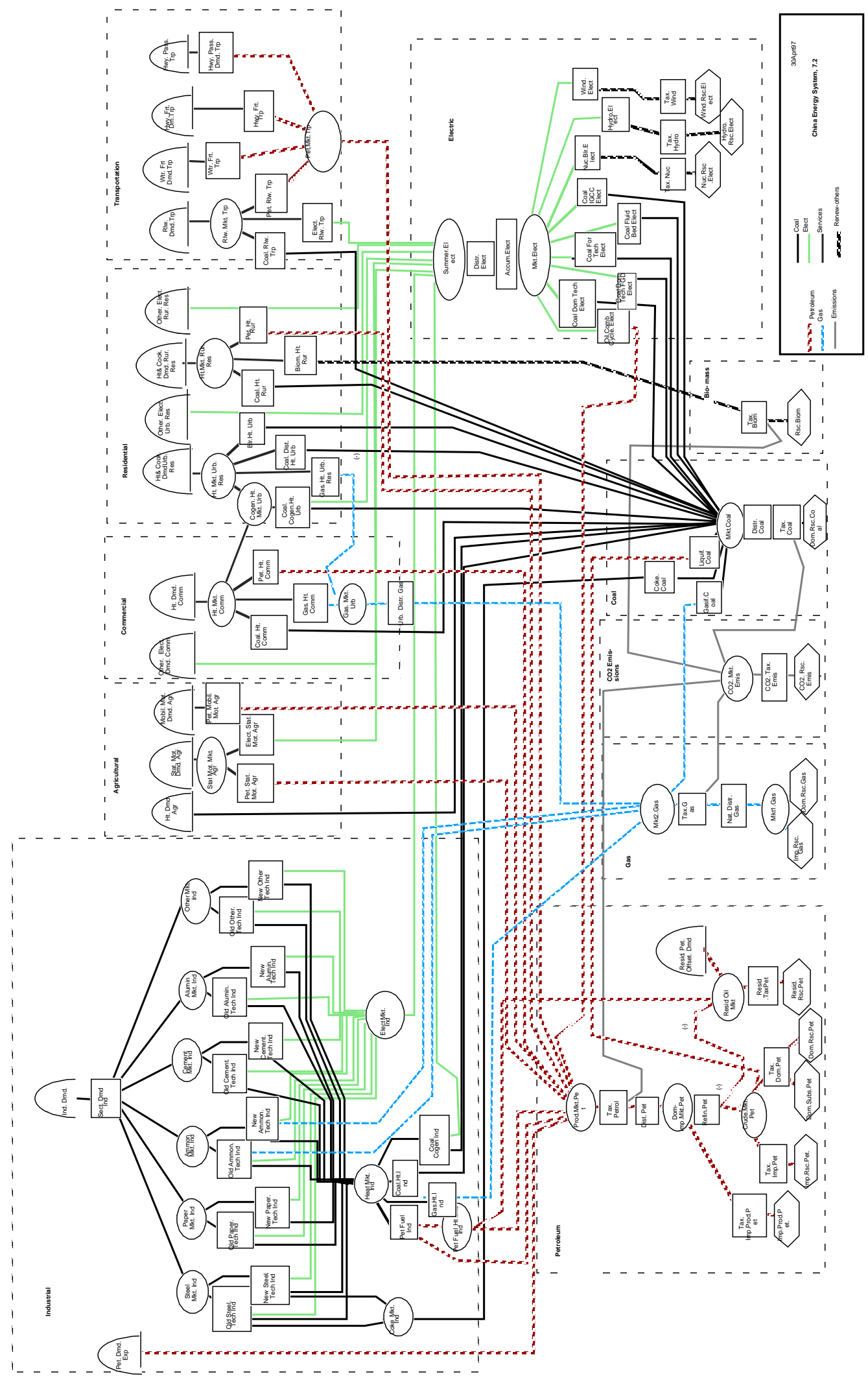


Nodes representing coal liquefaction and gasification are also included in the coal sector. The outputs from these nodes go to the petroleum and natural gas sectors.

Coal is used as a fuel for cogeneration and district heat in China. The way that this is modeled is described under the section for the electricity sector.

\subsubsection{Petroleum and refined petroleum products}

The model includes both domestic and foreign petroleum resources. The foreign resource is assumed to be purchased at a world price that simply escalates at a constant percentage rate over the model periods. The domestic resource is an exhaustible resource whose price does increase as more of the resource is used.

Considering that reliance on imported petroleum is a concern to the Chinese government and that policies have used in the past to reduce importation of petroleum, provisions are included in the model for quantity constraints or taxes on imported petroleum.

There is a single refining process in the model which converts crude petroleum into "refined petroleum products" and residual oil. The refined products are distributed through a single distribution process. Similar to coal, the parameters of the refining and distribution process has been set so that the resulting price of refined products is in the range of average prices in China.

Residual oil is considered to be a by-product of the refining process. The quantity produced is a simple function of the total amount of refined products produced. However, its price is set within the model so that the demand for residual oil is equal tot he production. Note that the revenues from the sale of residual oil are passed back to the refinery and reduce the price of refined products.

\subsubsection{Natural Gas}

The model provides for both domestic and imported natural gas. Currently, natural gas is not widely used in the Chinese economy. The prices have been set to reflect current average prices. Provisions have been included to represent the transportation and distribution of natural gas to the industrial, residential, and commercial sectors. 


\subsubsection{Biomass}

Biomass is assumed to be used primarily in the rural sector for heating where is competes with other fuels. A fixed annual quantity is made available (controlled through a constraint). The model finds a price level such that the total demand is equal to the total supply.

\subsubsection{Nuclear, Hydro and Wind}

These resources are modeled using simple structures. The nuclear is modeled as nuclear fuel resource fueling a nuclear generator. This price of the nuclear fuel escalates a fixed rate over time. There is no reprocessing or waste disposal process.

Wind and hydro electric power are modeled as resources with annual energy outputs that are constrained. It is assumed that the amount of wind or hydro resource available will be expanded over time (as long as there is a demand for it). So the amount assumed available each period grows according to a fixed schedule.

\subsubsection{End use Sectors}

The end-use sectors model the demand for energy services or, in the case of the industrial sector, for products with a significant energy content. In each case the final demands of the sector have been sub-divided into a few discrete uses. These are modeled using end-use nodes with constant elasticity demand functions. At each demand node it is assumed that the underlying demand grows following a set schedule. This growth is actually just a shift of the demand curve over time. This approach assumes that the sector of the population is growing typically through a growth in the population, but the underlying responsiveness to price changes remains constant. It is assumed that that structure of the Chinese economy will change over time and that the rates of growth of sectors will change. Consequently, the various sectors are not necessarily assumed to grow at the same rate, or even at a constant rate.

The structure of the sectors is described below.

\subsubsection{Industrial}

This sector is driven by a single node representing demand for industrial goods. This demand is supplied by six subsectors. We have modeled the five most energy intensive subsectors separately. The rest of industrial output is aggregated as other industrial products. 
It is envisioned that the model will be used to study the effects of improving the energy efficiency in various subsectors. To facilitate this, each subsector is represented by two process node: one for existing technology and one for more efficient future technology. The more efficient future technology can be allowed to penetrate and displace the existing technology over time.

In the current version, the industrial technologies require heat and electricity as their energy inputs. Heat is provided by a combination of coal, petroleum and natural gas. Electricity is represented directly as electricity. We note that the chemical industry actually has significant inputs of coal and natural gas feedstocks. At present, the demand for these inputs is represented as an equivalent demand for heat.

\subsubsection{Agricultural}

The primary uses of energy in the Agricultural sector are: process heat (largely for drying), static motors (pumps and processing machinery), and mobile machinery (tractors and trucks). The process heat is supplied primarily be coal. Static motors are fueled by both petroleum and electricity. And the mobile machinery is fueled by petroleum.

There is a substantial production of biomass in the form of crop residues. This is assumed to provide cooking and heating in the rural residential sector mentioned below.

\subsubsection{Residential}

The residential sector has been divided into rural and urban components. In both cases there is a demand for fuels for heating and cooking and a demand for other electrical energy. The demand for heating and cooking can be met through coal or petroleum. In the rural sector it can also be met through biomass. In the urban sector heating can cooking can also be met through natural gas, coal fired district heat, or district heat provided by coal-fired cogeneration.

\subsubsection{Commercial}

The commercial sector has demands for heating and cooling, and other electric. The heating and cooling can be provided by direct coal fired boilers, coal fired cogeneration, or coal fired district heat. 


\subsubsection{Transportation}

The transportation sector includes railway freight transportation (which can be provided by coal powered, diesel powered, or electric railways), highway freight transportation, water freight transportation, and highway passenger transportation.

\subsubsection{Electricity Sector}

Currently the bulk of electricity generation is provided by coal and hydro power. Current coal fired generators are represented by a single node resenting a typical generator built with domestic Chinese coal boiler technology.

Several advanced, clean coal technologies (CCTs) have also been included to allow study of their economic viability and impact that these may have on the energy system. These technologies are: integrated gasification and combined cycle generator, atmospheric fluidized bed, and advanced pulverized coal.

Hydro and wind power are represented by a combination of a power resource and a power conversion node. The price associated with the resource represents the operating cost of a hydro or wind facility and the conversion node represents the capital costs. The total output of the hydro conversion node is constrained over time to represent an estimate of the rate at which hydro power can be developed.

Nuclear power is represented as a combination of a resource representing the cost of fabricated fuel and a nuclear generator. It is assumed that the fuel will be purchased on the world market so its price is assumed to rise at a steady rate over time.

A single node has been included to represent the costs and the losses of the transmission and distribution system.

The META.Net modeling system can include simple load shape information and by dividing the total electric load into several portions with different load factors. It allocates each portion of the demand to the set of generation technologies that can serve each load factor most economically. The division of the total load is given in the appendix on model parameters. 


\subsection{Periods and time horizon}

The model uses a time horizon of fifty years, divided into ten five-year periods. The initial period is assumed to start in 1990. This is the most recent year for which we have reasonably complete data on the energy balance within the system.

\section{Base Case Results and Model Validation}

The base case run assumes that there will be no substantial introduction of new technologies, particularly in the industrial sector. It is primarily a projection of the effects of continuing with the current technologies out over a fifty year time horizon. The run provides two results. First it is a baseline projection of the impacts of a "do nothing" policy (one that we do not expect to be followed). Second, it provides the computed energy balance for the first period of the model (covering the years 1990-95). This first period energy balance can be compared against actual data as a way of validating the model results.

As is expected, the model results do not match the actual data exactly. The largest discrepancies are in coal supplies to the industrial and industrial sectors. In each case the discrepancy is about 100 million tons of coal equivalent (mtce) per year. In both cases the errors may be due to our assumptions about the average efficiencies of heating processes. 
Table 1: Comparisons of model results with actual energy commodity flows in China. Model data and actual data are for 1990. Quantities are in million tons coal equivalent (mtce). 1 ton coal equivalent is 29.3 giga Joules or 8,143 kWh. Data for the years 1990 - 1995 are taken from various tables in the China Energy Data Book.

\begin{tabular}{|l|l|l|l|}
\hline Sector & $\begin{array}{l}\text { Model } \\
\text { projections }\end{array}$ & $\begin{array}{l}\text { Actual flows } \\
\text { in 1990 }\end{array}$ & Comments \\
\hline Coal & & & \\
\hline Coal to industrial sector & 455 & 354 & \\
\hline Coal to agricultural sector & 18 & 15 & \\
\hline Coal to commercial sector & 22 & 22 & \\
\hline Coal to residential sector & 216 & 119 & \\
\hline Coal to transportation sector & 8 & 15 & \\
\hline Coal to electric sector & 169 & 196 & \\
\hline Other & 47 & 46 & 767 \\
\hline \hline total coal & 935 & & \\
\hline
\end{tabular}

\begin{tabular}{|l|l|l|l|}
\hline Sector & $\begin{array}{l}\text { Model } \\
\text { projections }\end{array}$ & $\begin{array}{l}\text { Actual flows } \\
\text { in 1990 }\end{array}$ & Comments \\
\hline Petroleum & & & \\
\hline Petroleum to industrial sector & 21 & 69 & \\
\hline Petroleum to agricultural sector & 7 & 10 & \\
\hline Petroleum to commercial sector & 2 & 5 & \\
\hline Petroleum to residential sector & 0 & 4 & \\
\hline $\begin{array}{l}\text { Petroleum to transportation } \\
\text { sector }\end{array}$ & 71 & 45 & \\
\hline Petroleum to electric sector & 2 & 23 & \\
\hline Petroleum exported & 33 & 32 & \\
\hline \hline total Petroleum & 137 & 157 & \\
\hline
\end{tabular}




\begin{tabular}{|l|l|l|l|}
\hline Sector & $\begin{array}{l}\text { Model } \\
\text { projections }\end{array}$ & $\begin{array}{l}\text { Actual flows } \\
\text { in 1990 }\end{array}$ & Comments \\
\hline Natural gas & & 13 & $\begin{array}{l}\text { includes } \\
\text { feedstocks }\end{array}$ \\
\hline Natural gas to industrial sector & 14 & 0 & \\
\hline $\begin{array}{l}\text { Natural gas to agricultural } \\
\text { sector }\end{array}$ & 0 & 0 & \\
\hline Natural gas to commercial sector & 2 & 2 & \\
\hline Natural gas to residential sector & 0 & 0 & \\
\hline $\begin{array}{l}\text { Natural gas to transportation } \\
\text { sector }\end{array}$ & 0 & 1 & \\
\hline Natural gas to electric sector & 1 & 16 & \\
\hline \hline total Natural gas & 17 & & \\
\hline
\end{tabular}

\begin{tabular}{|l|l|l|l|}
\hline Sector & $\begin{array}{l}\text { Model } \\
\text { projections }\end{array}$ & $\begin{array}{l}\text { Actual flows } \\
\text { in 1990 }\end{array}$ & Comments \\
\hline Electricity & & 48 & $\begin{array}{l}\text { accounts for } \\
\text { electricity from } \\
\text { cogeneration }\end{array}$ \\
\hline Electricity to industrial sector & 47 & 5 & \\
\hline Electricity to agricultural sector & 6 & 3 & \\
\hline Electricity to commercial sector & 4 & 6 & \\
\hline Electricity to residential sector & 7 & 1 & \\
\hline $\begin{array}{l}\text { Electricity to transportation } \\
\text { sector }\end{array}$ & 11 & 63 & \\
\hline \hline total Electricity & 75 & & \\
\hline
\end{tabular}

\section{Conclusions}

Under the project we have extended our modeling software and Improved our model of the Chinese energy system. These efforts have supported several analyses this year which contribute to our 
understanding of the environmental impacts of energy development and energy consuming technologies in China. This provides us with a firm foundation to explore ways in which innovations in energy technologies might penetrate the energy markets in China and reduce the overall emissions of both $\mathrm{CO} 2$ and sulfur.

\section{References}

Boyd, D., R. Phillips, and S. Regulinski "A Model of Technology Selection by Cost Minimizing Producers, Management Science, Vol. 28, No. 4, April 1982

Lamont, Alan, User's guide to the META Net economic modeling system, version 1.2, Lawrence Livermore National Laboratory, Livermore, Calif., UCRL-ID-122511, November 1994

Lamont, Alan "Modeling the impacts of a market for emissions permits", International Journal of Environmentally Conscious Design and Manufacturing, Vol. 5, No. 3-4, ECM Press, Albuquerque, NM, 1996 Lamont, Alan, Analysis of market penetration scenarios of clean coal technologies in China using the LLNL China energy model Lawrence Livermore National Laboratory, Livermore, Calif., UCRL-ID-131690, August 1998

Meltzer, M, A. Lamont, K. Gabor, and J. Stewart Analysis of the impact of alternative technologies on China's electric utility and industrial sectors. Lawrence Livermore National Laboratory, Livermore, Calif., UCRL-AR-132654 1998

Nakata, Toshihiko, Alan Lamont, and Jill Watz , "Impacts of CO2 Constraints on Energy Systems in Japan" presented at the 19th Annual North American Conference of the U.S. Association of Energy Economists /International Association of Energy Economists, Pages: 386-395, October 19,1998 


\section{Appendices}

\section{Appendix A: Derivation of input-output coefficients in industrial sector}

The industrial sector has been divided into six subsectors: Paper, Chemicals, Building Materials, Ferrous Metals, Nonferrous Metals, Other. The first five of these are energy intensive so they have been separated out to provide more resolution in the modeling. We have modeled the energy demands for each subsector as a function of their outputs. This section describes the analysis used to obtain the energy intensities for the subsectors for electric and non-electric energy. The analysis is based on data from the China Energy Data Book (CED 1996). For the energy intensive sectors.

For each subsector identified in the CED, we totaled up the electric and non-electric energy consumptions and converted these to tce. The CED also gives the total output for each subsector in Billion Yuan. We computed the energy intensity for each subsector in terms of electric and non-electric energy per billion Yuan of output. The model then computes the output for each subsector as a fraction of the total industrial output.

\section{Appendix B: Model input data}

This section lists the model parameters for version 9 of the model. In most cases a brief description of the source of the data, or a description of the analysis used to derived the parameters is provided. A number of the parameters are not documented. Many of these are not critical to the modeling, or are changed depending on the scenarios to be analyses with the model.

\section{Demand processes}

\section{Industrial sector demand}

Models the output of the industrial sector in Billion yuan per year 
Start quantity: 1196 B yuan/yr

From T 4-9.11 (CED 1996 ed.) Gross output value for manufacturing subtotal in 1980 yuan.

Demand growth: $0.041 / \mathrm{yr}$

Demand growth is the weighted average of three periods, 1990-2000 $(0.059 / \mathrm{yr}), 2000-2020(0.044 / \mathrm{yr})$ and $2020-2050(0.034 / \mathrm{yr})$. For the 2020-2050 period growth rate we used low growth assumption from Table 2.2 for the period 2000-2020. This number was selected only to illustrate the likely direction of growth for a mature economy. CLCE 1995 Tables 2.2, 2.3, 4.1. See Appendix for formula.

\section{Start price:}

This is not critical since this node is not price responsive. The price it receives is a composite price of the industrial subsectors. The prices for all except "Other" are in terms of yuan per ton output. The "other" sector is in current yuan per 1990 yuan of output. Currently $8.05 \mathrm{e} 2$ yuan.

It will be set to the value computed in preliminary runs.

Price growth: 0.0

Elasticity: $\quad-0.001$

\section{Petroleum demand (net exports)}

Start quantity: $33.24 \mathrm{Mtce} / \mathrm{yr}$

CED 1996 Ed T VII 1.3

Demand growth: 0.00/yr

Assume that petroleum exports will be small

Start price: $1.42 \mathrm{e} 3$ yuan/Mtce

Price is based on first period price calculated during model run

Price growth: $0.0 / \mathrm{yr}$

Elasticity: -0.001

\section{Coal Export Demand}

Start Quantity: $18.55 \mathrm{Mtce} / \mathrm{yr}$ 
Demand Growth: .02/y This number was chose to reflect the growth in this sector. The most recent periods show high growth, $10.5 \%$ and $17.3 \%$ respectively (CED $1996 \mathrm{~T} \mathrm{VII-1)}$ ). We expect this growth to level off and produce more moderate numbers.

Start Price: 500 yuan/tce

Price Growth: 0.00/yr

Elasticity: -0.001

Nominal Value

\section{Agricultural sector heat demand}

Represents the demand for coal for agricultural processing.

Start quantity: $15.55 \mathrm{Mtce} / \mathrm{yr}$

Start quantity based on demand of 15.55 Mtce for coal in 1990, CED 1996 Ed. T IV-17. Assume all coal is used for heat. (see also Agric Sector CED 1996 file)

\section{Demand growth: $0.051 / \mathrm{yr}$}

Based on Agricultural sector growth of 2.7\% Tables 2.2, 2.3, 4.1 CLCE 1995. (see appendix for demand growth formulas).Also based on projected increase in mechanization page 9 CLCE 1995 which equals $2.4 \%$.. ( see appendix for formulas combining growth and mechanization)

Start price: $6.27 \mathrm{e} 2$ yuan/Mtce Price is based on first period price calculated during model run

Price growth: $0.0 / \mathrm{yr}$

Elasticity: -0.1

\section{Agricultural sector static motor demand}

Start quantity: $5.14 \mathrm{Mtce} / \mathrm{yr}$

10.28 Mtce/yr for both static and mobile motor demand (CED T IV-17). Assume 50\% for each. (See Agric Sector CED 1996 file) Note that T IV-17 excludes diesel transportation.

Demand growth: $0.051 / \mathrm{yr}$ 
Based on Agricultural sector growth of 2.7\% Tables 2.2, 2.3, 4.1 CLCE 1995. (see appendix for demand growth formulas).Also based on projected increase in mechanization page 9 CLCE 1995 which equals $2.4 \%$.. (see appendix for formulas combining growth and mechanization)

Start price: $4.47 \mathrm{e} 3$ yuan/Mtce

Price is based on first period price calculated during model run

Price growth: $0.0 / y r$

Elasticity: -0.1

\section{Agricultural sector mobile motor demand}

Start quantity: $1.54 \mathrm{Mtce} / \mathrm{yr}$

Start quantity is based on CED T IV-17 and Agric Sector CED96 file. Static motors assumed to use $50 \%$ of agriculture diesel demand (10.28 Mtce) T IV-17. Assuming a motor efficiency of $30 \%$ results in $1.54 \mathrm{Mtce} / \mathrm{yr}$.

Demand growth: $0.051 / y r$

Based on Agricultural sector growth of 2.7\% Tables 2.2, 2.3, 4.1 CLCE 1995. (see appendix for demand growth formulas).Also based on projected increase in mechanization page 9 CLCE 1995, which equals $2.4 \%$. ( see appendix for formulas combining growth and mechanization)

Start price: $4.71 \mathrm{e} 3$ yuan/Mtce

Price is based on first period price calculated during model run

Price growth: $0.0 / \mathrm{yr}$

Elasticity: -0.1

Commercial sector other electric demand

Start quantity: $3.4 \mathrm{Mtce} / \mathrm{yr}$

Based on T IV-33 CED 96 which shows Commercial sector other electric consumption in period 1 (1990) is $27.86 \mathrm{TWh}$, which is equivalent to 3.42 Mtce .

Demand growth: $0.058 / y r$ 
Projected growth of commercial sector over 60 years Tables 2.2, 2.3, 4.1 CLCE 1995 (see appendix for formulas)

Start price: $4.01 \mathrm{e} 3$ yuan/Mtce

Price is based on first period price calculated during model run

Price growth: $0.0 / \mathrm{yr}$

Elasticity: -0.16

Commercial sector heat demand

Start quantity: $26.19 \mathrm{Mtce} / \mathrm{yr}$

Based upon an energy consumption of 29.10 Mtce in T IV-23, 1990, which is the sum of coal, heat, liquids and gas, and an assumption of 0.9 efficiency. See 'Comm. Sector CED96 file.

Demand growth: $0.058 / y r$

Projected growth of commercial sector over 60 years Tables 2.2, 2.3, 4.1 CLCE 1995 (see appendix for formulas)

Start price: $1.11 \mathrm{e} 3$ yuan/Mtce

Price is based on first period price calculated during model run

Price growth: $0.0 / \mathrm{yr}$

Elasticity: -0.15

Residential sector urban heating and cooking demand

Start quantity: 59.21 Mtce

Use start quantity of 59.21 Mtce (see Resident Sector CED 1996 ). Heating and cooking demand based on the difference of energy into total residential sector T IV -18.2 150.3 Mtce-19.4 Mtce (electricity) $=130.9$ Mtce total residential non-electric demand. To derive the Urban residential demand alone, subtract out the rural residential sector consumption of coal and oil product $\mathrm{s}, 65.11$ Mtce (T IV-21). 130.9 Mtce-65.11 Mtce $=65.79$ Mtce. Assume an efficiency of 0.9. Actual heat demand is 65.79 Mtce * $0.9=59.21$ Mtce.

Demand growth: $0.054 / y r$

Based on per capita GNP 0.039/yr Tables 2.2 and 4.1 (CLCE 1995 ) and shift in pop to urban centers 0.015/yr page 5 (CLCE 1995 ) See appendix for formulas 
Start price: $7.27 e 2$ yuan/Mtce

Price is based on first period price calculated during model run

Price growth: $0.0 / \mathrm{yr}$

Elasticity: -0.05

\section{Residential sector urban other electric demand}

Start quantity: $5.2 \mathrm{Mtce} / \mathrm{yr}$

The total residential electrical energy consumption was $48.1 \mathrm{TWh}$, or 5.9 Mtce, in 1990 (T IV-18.1). Rural household consumption is shown as 2.12 Mtce in 1990 (T IV-21 CED 1996ed). However, in most tables, it was found that the electricity consumption when measured in Mtce was actually the amount of coal required to produce the given amount of electricity. Therefore, assuming an efficiency of about $1 / 3$, we estimate that the rural electric consumption was about 0.7 Mtce of electric energy in 1990. The residential urban demand is estimated as $5.9-0.7$ Mtce $=5.2$ Mtce of electric energy.

Demand growth: $0.054 / \mathrm{yr}$

Based on per capita GNP 0.039/yr Tables 2.2 and 4.1 (CLCE 1995 ) and shift in pop to urban centers 0.015/yr page 5 (CLCE 1995 ) See appendix for formulas

Start price: $4.01 \mathrm{e} 3$ yuan/Mtce

Price is based on first period price calculated during model run

Price growth: $0.0 / \mathrm{yr}$

Elasticity: -0.08

\section{Residential sector rural heating and cooking demand}

Start quantity: $328.54 \mathrm{Mtce} / \mathrm{yr}$

Start quantity equal to sum of Biomass, Coal and Oil product consumption from CED 96 T IV-21. The breakout is 263.03 Mtce household biomass, 64.29 Mtce of coal, and 1.22 Mtce petroleum

Demand growth: $0.028 / y r$.

Based on per capita GNP 0.039/yr Tables 2.2 and 4.1 CLCE 1995 and shift in pop away from rural areas -0.011. Page 5 and table 2.1 CLCE. The decrease in rural population causes the expected rural electric 
demand to grow at a slower rate than the per capita GNP. See appendix for formulas.

Start price: $2.55 \mathrm{e} 2$ yuan/Mtce

Price is based on first period price calculated during model run

Price growth: $0.0 / \mathrm{yr}$

Elasticity: -0.05

\section{Residential sector rural other electric demand}

Start quantity: $0.7 \mathrm{Mtce} / \mathrm{yr}$

Rural household consumption is shown as 2.12 Mtce in 1990 (T IV-21

CED 1996ed). However, in most tables, it was found that the electricity consumption when measured in Mtce was actually the amount of coal required to produce the given amount of electricity. Therefore, assuming an efficiency of about $1 / 3$, we estimate that the rural electric consumption was about 0.7 Mtce of electric energy in 1990..

Demand growth: $0.028 / y r$.

Based on per capita GNP 0.039/yr Tables 2.2 and 4.1 CLCE 1995 and shift in pop away from rural areas -0.011 . Page 5 and table 2.1 CLCE. The decrease in rural population causes the expected rural electric demand to grow at a slower rate than the per capita GNP. See appendix for formulas.

Start price: $2.06 \mathrm{e} 5$ yuan/Mtce

Price is based on first period price calculated during model run

Price growth: $0.0 / \mathrm{yr}$

Elasticity: -0.08

\section{Transportation sector railway demand}

Start quantity: 1062.24 Billion Tons-km

Based on CED96, T V-1 railway freight demand of 1062.24 Billion Tons$\mathrm{Km}$ ) and $\mathrm{T} \mathrm{V}-2$ railway passenger demand, 261.26 Billion Passengers$\mathrm{km}$. Use only freight demand. Passenger tones is less than $1 \%$ of total tons and can be neglected.

Demand growth: $0.043 / y r$ 
See Note 2.

Start price: $8.9 \mathrm{e} 5$ yuan/B Tons-km

Price is based on first period price calculated during model run

Price growth: $0.0 / \mathrm{yr}$

Elasticity: -0.04

Transportation sector water freight demand

Start quantity: 1159.19 B ton-km/yr

Start quantity based on 1990 demand of 1159.19 B ton-km in CED $1996 \mathrm{ed}, \mathrm{T}$ V-1 (sum of river and ocean)

Demand growth: $0.043 / y r$

See Note 2.

Start price: $2.06 \mathrm{e} 5$ yuan/B ton-km

Price is based on first period price calculated during model run

Price growth: $0.0 / \mathrm{yr}$

Elasticity: -0.04

Transportation sector highway freight demand

Start quantity: $335.81 \mathrm{~B}$ tone-km/yr

Start quantity based on 1990 demand. CED 1996ed T V-1

Demand growth: $0.043 / y r$

See Note 2.

Start price: $8.9 \mathrm{e} 5$ yuan/B ton $\mathrm{km}$

Price is based on first period price calculated during model run

Price growth: 0

Elasticity: -0.04

Transportation sector highway passenger demand

Start quantity: 262.03 B pass-km/yr

Start quantity based on 1990 demand. CED 1996ed T V-2

Demand growth: $0.039 / \mathrm{yr}$ 
Based on projected per capita GNP growth of 0.039/yr Table 4.1 CLCE 1995

Start price: $1.01 \mathrm{e} 5$ yuan/B pass-km

Price is based on first period price calculated during model run

Price growth: 0

Elasticity: -0.11

Residual petroleum offset demand

Start quantity: 50

This is a small demand used to ensure that the total quantity passed down is greater than 0.0. This makes the convergence of the model easier. This is an arbitrary amount that is scaled to work effectively with the model solution algorithm.

Demand growth: $0.0 / y r$

Start price: $7.32 \mathrm{e} 2$ yuan/Mtce

Price is based on first period price calculated during model run

Price growth: 0

Elasticity: $\quad-0.0001$

Input nodes: Residual oil market

\section{Markets}

Industrial sector ferrous metals market

Market sensitivity: 5

Pass constraint prices: true

Industrial sector paper market

Market sensitivity: 5

Pass constraint prices: true

Industrial sector Chemical market

Market sensitivity: 5

Pass constraint prices: true 
Industrial sector Building Material market

Market sensitivity: 5

Pass constraint prices: true

Industrial sector aluminum market

Market sensitivity: 5

Pass constraint prices: true

Industrial sector other market

Market sensitivity: 5

Pass constraint prices: true

Industrial sector coke market

Market sensitivity: 5

Pass constraint prices: true

Industrial sector heat market

Market sensitivity: 5

Pass constraint prices: true

Industrial sector petroleum fuel market

Market sensitivity: 5

Pass constraint prices: true

Industrial petroleum fuel heat

Market sensitivity: 5

Pass constraint prices: true

Industrial sector electric market

Market sensitivity: 5

Pass constraint prices: true

Agricultural sector static motor market Market sensitivity: 5 
Pass constraint prices: true

Commercial sector heat market

Market sensitivity: 5

Pass constraint prices: true

Commercial sector

Output nodes: Commercial heat demand

urban gas market

Market sensitivity: 5

Pass constraint prices: true

Residential sector urban heat market

Market sensitivity: 5

Pass constraint prices: true

Residential sector urban cogeneration heat market

Market sensitivity: 5

Pass constraint prices: true

Residential sector rural heat market

Market sensitivity: 5

Pass constraint prices: true

Transportation sector railway market

Market sensitivity: 5

Pass constraint prices: true

Transportation sector petroleum market

Market sensitivity: 5

Pass constraint prices: true 
Petroleum product market

Market sensitivity: 5

Pass constraint prices: true

Petroleum sector crude market

Market sensitivity: 10

Pass constraint prices: true

Residual oil market

Market sensitivity: 5

Pass constraint prices: true

Gas market 1

Market sensitivity: 10

Pass constraint prices: true

Gas market 2

Market sensitivity: 5

Pass constraint prices: true

Coal market

Market sensitivity: 5

Pass constraint prices: true

Electric market "summer"

Market sensitivity: 5

Pass constraint prices: true

Electric market

Market sensitivity: 30

Pass constraint prices: false

CO2 emissions market

Market sensitivity: 5 
Pass constraint prices: true

\section{Sulfur emissions market}

Market sensitivity: 5

Pass constraint prices: true

\section{Contracts}

None included in this model

\section{Conversion processes}

Note: For conversions nodes where the minimum capacity factor value is not critical (VNC), a nominal value of 0.7 was used.

\section{Industrial sector demands}

This node divides the total industrial demand into the demands for each subsector.

Output: Billion yuan in 1990 yuan

Input: B Yuan of product

Capacity: 1,196 B yuan/yr

From T IV-9 CED96 for 1990

Capital and operating costs:

Capital Cost: 0 yuan

No value required at this time since this node is used to determine demands for energy inputs

Operating Cost: 0 yuan/yr

Value is not critical since this node is used to determine demands for energy inputs

Life: 25 yrs

Availability factor: 1.0

Minimum capacity factor: 0.7

\section{I-O coefficients:}


In terms of Billion Yuan of output per Billion yuan of total industrial output.

From Industrial ferrous metals market: 0.057

From Industrial paper market: 0.028

From Industrial Chemical market: 0.090

From Industrial Building Material market: 0.076

From Industrial aluminum market: 0.025

From Industrial other market: 0.720

Old Ferrous metals Technology

Output: B Yuan of output

Input: Mtce

Capacity: $68.5 \mathrm{BY} /$ year

From T IV-9 CED 96 for 1990

Capital and operating costs:

Capital Cost: 0

No value required at this time since this node is used to determine demands for energy inputs

Operating Cost: 0

No value required at this time since this node is used to determine demands for energy inputs

Life: 25 yrs

Availability factor: 1.0

Minimum capacity factor: 0.7

\section{I-O coefficients:}

From Industrial coke market: 0.01

Set to a small number since coke is already included in the total demand for ferrous metals.

From Industrial heat market: 1.53

From Industrial electric market: 0.10 
New Ferrous metals Technology

Output: B Yuan of output

Input: Mtce

Capacity: 16 MTons/yr

Capital and operating costs:

Capital Cost: 0

No value required at this time since this node is used to determine demands for energy inputs.

Operating Cost: $10,000 \mathrm{Y} / \mathrm{Mtons}$

Priced out of market at this time

Life: 25 yrs

Availability factor: 1.0

Minimum capacity factor: 0.7

\section{I-O coefficients:}

From Industrial coke market: 0.01

Set to a small number since coke is already included in the total demand for ferrous metals.

From Industrial heat market: 0

From Industrial electric market: 0

\section{Old Paper Technology}

Output: B Yuan of output

Input: Mtce

Capacity: $32.9 \mathrm{~B}$ Y/ year

From T IV-9 CED 96 for 1990

Capital and operating costs:

Capital Cost: 0

No value required at this time since this node is used to determine demands for energy inputs.

Operating Cost: 0

No value required at this time since this node is used to determine demands for energy inputs 
Life: 25 yrs

Availability factor: 1.0

Minimum capacity factor: 0.7

I-O coefficients:

From Industrial heat market: 0.53

From Industrial electric market: 0.04

\section{New Paper Technology}

Output: B Yuan of output

Input: Mtce

Capacity: 16 Mtce/year

Capital and operating costs:

Capital Cost: 0

No value required at this time since this node is used to determine demands for energy inputs

Operating Cost: 0

No value required at this time since this node is used to determine demands for energy inputs

Life: 25 yrs

Availability factor: 1.0

Minimum capacity factor: 0.7

I-O coefficients:

From Industrial heat market: 0.95

From Industrial electric market: 0.08

\section{Old Chemical Technology}

Output: B Yuan of output

Input: Mtce

Capacity: $107.1 \mathrm{~B}$ Y/ year

From T IV-9 CED 96 for 1990

Capital and operating costs: 
Capital Cost: 0

No value required at this time since this node is used to determine demands for energy inputs.

Operating Cost: 0

No value required at this time since this node is used to determine demands for energy inputs

Life: 25 yrs

Availability factor: 1.0

Minimum capacity factor: 0.7

\section{I-O coefficients:}

From Industrial heat market: 1.05

From Industrial electric market: 0.08

From Industrial Gas Market: 0.060

\section{New Chemical Technology}

Output: B Yuan of output

Input: Mtce

Capacity: 16 Mtce/yr

Capital and operating costs:

Capital Cost: 0

No value required at this time since this node is used to determine demands for energy inputs.

Operating Cost: 10,000 Y/MTon

Priced out of market

Life: 25 yrs

Availability factor: 1.0

Minimum capacity factor: 0.7

\section{I-O coefficients:}

From Industrial heat market: 0

From Industrial electric market: 0

From Industrial Gas Market: 0 


\section{Old Building Material Technology}

Output: B Yuan of output

Input: Mtce

Capacity: $90.5 \mathrm{~B} \mathrm{Y/ \text {year }}$

From T IV-9 CED 96 for 1990

Capital and operating costs:

Capital Cost: 0

No value required at this time since this node is used to determine demands for energy inputs

Operating Cost:

No value required at this time since this node is used to determine demands for energy inputs

Life: 25 yrs

Availability factor: 1.0

Minimum capacity factor: 0.7

\section{I-O coefficients:}

From Industrial heat market: 0.90

From Industrial electric market: 0.04

\section{New Building Material Technology}

Output: B Yuan of output

Input: Mtce

Capacity: 16 Mtce/yr

Capital and operating costs:

Capital Cost:

No value required at this time since this node is used to determine demands for energy inputs

Operating Cost: 10,000 Y/MTon

No value required at this time since this node is used to determine demands for energy inputs

Life: 25 yrs

Availability factor: 1.0 


\section{Minimum capacity factor: 0.7}

\section{I-O coefficients:}

From Industrial heat market: 0

From Industrial electric market: 0

\section{Old Aluminum Technology}

Output: B Yuan of output

Input: Mtce

Capacity: $29.9 \mathrm{~B} \mathrm{Y/ \text {year }}$

From T IV-9 CED 96 for 1990

Capital and operating costs:

Capital Cost: 0

No value required at this time since this node is used to determine demands for energy inputs

Operating Cost: 0

No value required at this time since this node is used to determine demands for energy inputs

Life: 25 yrs

Availability factor: 1.0

Minimum capacity factor: 0.7

\section{I-O coefficients:}

From Industrial heat market: 0.34

From Industrial electric market: 0.11

\section{New Aluminum Technology}

Output: B Yuan of output

Input: Mtce

Capacity: 16 Mtce/yr

Capital and operating costs:

Capital Cost: 0

No value required at this time since this node is used to determine demands for energy inputs 
Operating Cost: 10,000 Y/B Tons

Priced out of market

Life: 25 yrs

Availability factor: 1.0

Minimum capacity factor: 0.7

I-O coefficients:

From Industrial heat market: 0

From Industrial electric market: 0

Old Other Technology

Output: B Yuan of output

Input: Mtce

Capacity: $867.1 \mathrm{~B} \mathrm{Y/} \mathrm{year}$

From T IV-9 CED 96 for 1990

Capital and operating costs:

Capital Cost: 0

No value required at this time since this node is used to determine demands for energy inputs

Operating Cost: 0

No value required at this time since this node is used to determine demands for energy inputs

Life: 25 yrs

Availability factor: 1.0

Minimum capacity factor: 0.7

I-O coefficients:

in units of Mtce/B $Y$ of output

From Industrial heat market: 0.17

From Industrial electric market: 0.02

New Other Technology

Output: B Yuan of output

Input: Mtce 
Capacity: 16 Mtce/ year

Capital and operating costs:

Capital Cost: 0

No value required at this time since this node is used to determine demands for energy inputs

Operating Cost: 10,000 Y/B Yuan

Priced out of market

Life: 25 yrs

Availability factor: 1.0

Minimum capacity factor: 0.7

\section{I-O coefficients:}

in units of Mtce/BY of output

From Industrial heat market: 0.181

From Industrial electric market: 0.19

\section{Industrial sector petroleum fuel heat}

Output: Mtce

Input: Mtce

Capacity: 26 Mtce/yr

Based on sum of petroleum use for industry in T IV-9 CED 96 for 1990.

Capital and operating costs:

Capital Cost: $681 \mathrm{Y} / \mathrm{tce} / \mathrm{yr}$

Based on using $50 \%$ of LLEM cost for Indirect (Steam) Heat. Note: assume use of steam heat, which is more efficient than direct heat.

Operating Cost: $48 \mathrm{Y} / \mathrm{tce} / \mathrm{yr}$

Based on using $50 \%$ of LLEM cost for Indirect (Steam) Heat. Note: assume use of steam heat, which is more efficient than direct heat.

Life: 25 yrs

Availability factor: 1.0

Minimum capacity factor: 0.7

\section{I-O coefficients:}

From Industrial petroleum fuel market: 1 


\section{Industrial sector gas heat}

Currently this also represents the demand for feedstocks

Output: Mtce

Input: Mtce

Capacity: 20 Mtce/yr

Based on sum of natural gas use for industry in T IV-9 CED 96 for 1990.

Capital and operating costs:

Capital Cost: 609 yuan/Mtce/yr

Based on using $50 \%$ of LLEM costs for Indirect (Steam) Gas Heat

Operating Cost: 39 yuan/Mtce/yr

Based on using $50 \%$ of LLEM90 costs for Indirect (Steam) Gas Heat

Life: 25 yrs

Availability factor: 1.0

Minimum capacity factor: 0.7

\section{I-O coefficients:}

From gas market: 1

Industrial sector coal heat

Output: Mtce

Input: Mtce

Capacity: $299 \mathrm{Mtce} / \mathrm{yr}$

Based on sum of coal use for industry in T IV-9 CED96 for 1990.

Capital and operating costs:

Capital Cost: 1458 yuan/ tce/yr

Based on using $50 \%$ of LLEM costs for Indirect (Steam) Coal Heat

Operating Cost: 54 yuan/tce/yr

Based on using $50 \%$ of LLEM costs for Indirect (Steam) Coal Heat

Life: 25 yrs

Availability factor: 1.0 


\section{Minimum capacity factor: 0.7}

\section{I-O coefficients:}

From coal market: 1

From sulfur emissions market: 0.015 (See Note 1)

\section{Industrial sector coal cogeneration}

Provides heat to the industrial sector and returns electricity to the electric grid.

Table IV-26 of CED '96 shows 21.4 Mtce input to heat for 1990 . The footnote indicates that this produces heat from cogeneration and dedicated heat plants and sold to industrial and other sectors. We assume that about half this coal goes into the industrial sector. The output of the node will be constrained to 10 Mtce per year for the first period. We will allow it to expand at $5 \%$ per year.

Output: Mtce heat

\section{Input:}

From coal market: Mtce

From electric summer: Mtce negative quantity of electricity which models electricity returned to the grid

Capacity: 35 Mtce/yr

Adjusted to match results from first period of model run

\section{Capital and operating costs:}

Capital Cost: 8,357 yuan/(tce/yr)

from Sinton (July 1996)

Operating Cost: 167 yuan/tce assume operating costs per unit output are $2 \%$ of capital costs per unit capacity based on typical values for coal plants in EPRI TAG (1989)

Life: 25 yrs

Availability factor: 0.7 on the low side for coal power plants based on EPRI TAG (1989)

Minimum capacity factor: 0.4

\section{I-O coefficients:}


From coal market: 1.41

from GRI (p 9-9)

From electric summer: -0.14

from GRI (p 9-9) the electrical output is approximately $10 \%$ of the heat output

From sulfur emissions market: 0.022 (see Note 1)

\section{Agricultural Emissions}

This node has been inserted to allow computation of the emissions from using coal in the agricultural sector. It is not assigned a cost.

Output: Mtce

Input: Mtce

Capacity: 1 Mtce/yr

Capital and operating costs:

Capital Cost: $0 \mathrm{Y} / \mathrm{Tce} / \mathrm{yr}$

Operating Cost: $0 \mathrm{Y} / \mathrm{Tce} / \mathrm{yr}$

Life: 25 yrs

Availability factor: 1.0

Minimum capacity factor: 0.7

\section{I-O coefficients:}

From sulfur emissions market: 0.015 (see Note 1)

From coal market: 1

\section{Agricultural sector static petroleum motor}

Output: Mtce

Input: Mtce

Capacity: $8 \mathrm{Mtce} / \mathrm{yr}$

Capital and operating costs:

Capital Cost: 110 yuan/(tce/yr)

Based on analogous process(es) in LLEM. 
Operating Cost: 10 yuan/tce

Based on analogous process(es) in LLEM90.

Life: 25 yrs

Availability factor: 1.0

Minimum capacity factor: 0.7

\section{I-O coefficients:}

From product market petroleum: 3.3

Assuming about 0.33 efficiency.

Agricultural sector static electric motor

Output: Mtce

Input: Mtce

Capacity: 7 Mtce/yr

Capital and operating costs:

Capital Cost: 3748 yuan/ (tce/yr)

Based on using $50 \%$ of LLEM costs for Conventional Electric Heat Pump

Operating Cost: 89 yuan/tce

Based on using $50 \%$ of LLEM costs for Conventional Electric Heat

Pump

Life: 30 yrs

Availability factor: 1.0

Minimum capacity factor: 0.7

I-O coefficients:

From summer electric 1.02

Assuming 0.98 efficiency.

Agricultural sector mobile petroleum motor

Output: Mtce

Input: Mtce

Capacity: 1 Mtce/yr

Capital and operating costs: 
Capital Cost: 110 yuan/ (tce/yr)

Based on analogous process(es) in LLEM.

Operating Cost: 10 yuan/tce

Based on analogous process(es) in LLEM90.

Life: 25 yrs

Availability factor: 1.0

Minimum capacity factor: 0.7

\section{I-O coefficients:}

From product market petroleum: 3.3

Assume motors are about $30 \%$ efficient

Commercial sector coal heat

Output: Mtce

Input: Mtce

Capacity: $20 \mathrm{Mtce} / \mathrm{yr}$

Capital and operating costs:

Capital Cost: 8184 yuan/ (tce/yr)

Based on estimate of $100 \%$ more expensive than Petroleum Heat

Operating Cost: 510 yuan/tce

Based on same estimate as Petroleum Heat

Life: 25 yrs

Availability factor: 1.0

Minimum capacity factor: 0.7

\section{I-O coefficients:}

From sulfur emissions market: 0.017 (Note 1)

From coal market: 1.1

Assume about $90 \%$ efficiency

Commercial sector petroleum heat

Output: Mtce

Input: Mtce 
Capacity: 3 Mtce/yr

Capital and operating costs:

Capital Cost: 4092 yuan/ tce/yr

Based on LLEM data for Conventional Distillate Heat

Operating Cost: 510 yuan/tce

Based on estimate for Conventional Distillate Heat

Life: 25 yrs

Availability factor: 1.0

Minimum capacity factor: 0.7

I-O coefficients

From product market petroleum 1.1

Commercial sector gas heat

Output: Mtce

Input: Mtce

Capacity: 3 Mtce/yr

Capital and operating costs:

Capital Cost: 5122 yuan/ (tce/yr)

Based on LLEM data for Conventional Gas Heat

Operating Cost: 441 yuan/tce

Based on LLEM data for Conventional Gas Heat

Life: 25 yrs

Availability factor: 1.0

Minimum capacity factor: 0.7

\section{I-O coefficients:}

From gas market urban: 1.1

Urban gas distribution (Commercial and Residential sector)

Output: Mtce

Input: Mtce 
Capacity: 3 Mtce/yr

Capital and operating costs:

Capital Cost: 1917 yuan/tce

Based on LLEM data for HBTU gas transportation

Operating Cost: 40 yuan/tce/yr

Based on LLEM data for HBTU gas transportation

Life: 25 yrs

Availability factor: 1.0

Minimum capacity factor: 0.7

I-O coefficients:

From market 2 gas 1.01

Residential sector urban district coal heat distribution

Output: Mtce

Input: Mtce

Capacity: $4 \mathrm{Mtce} / \mathrm{yr}$

Capital and operating costs:

Capital Cost: 1458 yuan/ (tce/yr)

Based on data from LLEM for Industrial Coal (Steam) Heat

Operating Cost: 54 yuan/ tce

Based on data from LLEM for Industrial Coal (Steam) Heat

Life: 25 yrs

Availability factor: 1.0

Minimum capacity factor: 0.7

I-O coefficients:

From coal market: 1.72

Based on using data for Industrial Coal (Steam) Heat in LLEM

From sulfur emissions market: 0.026 (see Note 1) 
Residential sector urban coal heat cogeneration

Output: Mtce

\section{Input:}

From coal market: Mtce

From electric summer: negative quantity of electricity which is returned to the grid

Capacity: 7 Mtce/yr

Capital and operating costs:

Capital Cost: 8,357 yuan/(tce/yr) from Sinton (July 1996)

Operating Cost: 167 yuan/tce

Assume operating costs per unit output are $2 \%$ of capital costs per

unit capacity based on typical values for coal plants in EPRI TAG (1989)

Life: 25 yrs

Availability factor: 0.7 on the low side for coal power plants based on EPRI TAG (1989)

Minimum capacity factor: 0.4

\section{I-O coefficients:}

From coal market: 1.41 from GRI (p 9-9)

From electric summer: -0.14 from GRI ( $p$ 9-9) the electrical output is approximately $10 \%$ of the heat output

From sulfur emissions market: 0.022 (see Note 1)

Residential sector urban heat boiler (Coal District Heat)

Output: Mtce

Input: Mtce

Capacity: 52 Mtce/yr

Capital and operating costs:

Capital Cost: 84 yuan

Operating Cost: 3.2 yuan/yr

Life: 25 yrs

Availability factor: 1.0 
Minimum capacity factor: 0.7

I-O coefficients:

From coal market: 1.1

Assume about $90 \%$ efficient

From sulfur emissions market: 0.017 (see Note 1)

Residential sector urban gas heat

Output: Mtce

Input: Mtce

Capacity: $3 \mathrm{Mtce} / \mathrm{yr}$

Capital and operating costs:

Capital Cost: 5122 yuan/ (tce/yr)

Based on converting US costs for Conventional Gas Heat LLEM to China's.

Operating Cost: 441 yuan/tce

Based on converting US costs for Conventional Gas Heat LLEM to China's.

Life: 25 yrs

Availability factor: 1.0

Minimum capacity factor: 0.7

\section{I-O coefficients:}

From gas market urban: 1.1

Assume about $90 \%$ efficient

\section{Residential sector rural coal heat}

Output: Mtce

Input: Mtce

Capacity: $80 \mathrm{Mtce} / \mathrm{yr}$

Capital and operating costs:

Capital Cost: 100 yuan/ (tce/yr)

Estimated cost of simple coal stove 
Operating Cost: 2 yuan/tce

Estimated cost of simple coal stove

Life: 25 yrs

Availability factor: 1.0

Minimum capacity factor: 0.7

I-O coefficients:

From coal market: 1.1

Assume about $90 \%$ efficient

From sulfur emissions market: 0.017 (see Note 1)

Residential sector rural biomass heat

Output: Mtce

Input: Mtce

Capacity: 307 Mtce/yr

Capital and operating costs:

Capital Cost: 100 yuan/ (tce/yr)

Estimated cost of simple stove

Operating Cost: 0.1 yuan/tce

Estimated operating cost of a simple stove

Life: 10 yrs

Availability factor: 1.0

Minimum capacity factor: 0.7

\section{I-O coefficients:}

From tax biomass: 1.1

Assume about $90 \%$ efficient.

Residential sector rural petroleum heat

Output: Mtce

Input: Mtce

Capacity: $0 \mathrm{Mtce} / \mathrm{yr}$ 
Capital and operating costs:

Capital Cost: 2867 yuan/ (tce/yr)

Based on converting US costs for Residential Distillate Heat in LLEM to China's costs.

Operating Cost: 190 yuan/tce

Based on converting US costs for Residential Distillate Heat in LLEM to China's costs.

Life: 25 yrs

Availability factor: 1.0

Minimum capacity factor: 0.7

\section{I-O coefficients:}

From product market petroleum: 1.1

Assume about $90 \%$ efficient

Transportation sector coal railway

Output: B ton km

Input: $B$ ton $\mathrm{km}$

Capacity: $248 \mathrm{Mtce} / \mathrm{yr}$

Capital and operating costs:

Capital Cost: 4e7 yuan/ (B ton-km/yr) B ton-km

Based on converting US costs for Diesel Train in LLEM to China's costs.

Operating Cost: $6 \mathrm{e} 6$ yuan/ B ton-km

Based on converting US costs for Diesel Train in LLEM to China's costs. See appendix.

Life: 25 yrs

Availability factor: 1.0

Minimum capacity factor: 0.7

I-O coefficients:

From coal market: 0.0325 .

Based on 1990 (CED96 T V-4 and IV-16) amount of steam locomotive demand units (6279), haulage per unit tons (2120), and fuel demand 
(14.7 Mtce). Thus, $14.7 /((6279 * 2120 * 33979 / 1 \mathrm{e} 9))=0.0325$

efficiency in Mtce/B ton-km. See Trans sector CED 1996 file for details.

From sulfur emissions market: 0.001 See Note 1

Transportation sector electric railway

Output: B ton km

Input: $B$ ton $\mathrm{km}$

Capacity: 758 B ton-km/yr

Capital and operating costs:

Capital Cost: 4e7 yuan/ (Bton-km/yr)

Based on converting US costs for Diesel Train in LLEM to China's costs.

Operating Cost: 4e6 yuan/ B ton-km

Based on converting US costs for Diesel Train in LLEM to China's costs.

Life: 25 yrs

Availability factor: 1.0

Minimum capacity factor: 0.7

\section{I-O coefficients:}

From summer electric 0.019223 .

See Trans Sector CED 1996 file for details.

\section{Transportation sector petroleum railway}

Output: B ton km

Input: $B$ ton $\mathrm{km}$

Capacity: 420 Mtce/yr

Capital and operating costs:

Capital Cost: $4 \mathrm{e} 7 \mathrm{yuan} /$ (B ton $\mathrm{km} / \mathrm{yr}$ )

Based on converting US costs for Diesel Train in LLEM to China's costs.

Operating Cost: $5 \mathrm{e} 6$ yuan/ B ton km

Based on converting US costs for Diesel Train in LLEM to China's costs.

Life: 25 yrs 
Availability factor: 1.0

Minimum capacity factor: 0.7

I-O coefficients:

From transportation petroleum market 0.0085

See Trans sector CED 1996 file for details.

Transportation sector water freight

Output: B ton km

Input: $B$ ton $\mathrm{km}$

Capacity: 1099 (B ton $\mathrm{km} / \mathrm{yr}$ )

Capital and operating costs:

Capital Cost: $6 \mathrm{e} 4 \mathrm{yuan} /(\mathrm{B}$ ton $\mathrm{km} / \mathrm{yr})$

Based on converting US costs for Marine Diesel in LLEM to China's costs.

Operating Cost: 2e5 yuan/ B ton km

Based on converting US costs for Marine Diesel in LLEM to China's costs.

Life: 25 yrs

Availability factor: 1.0

Minimum capacity factor: 0.7

\section{I-O coefficients:}

From petroleum market transportation 0.138

See Trans Sector CED 1996 file.

\section{Transportation sector highway freight}

Output: B ton km

Input: $B$ ton $\mathrm{km}$

Capacity: 351 Mtce/yr

Capital and operating costs:

Capital Cost: $2 \mathrm{e} 5 \mathrm{yuan} /(\mathrm{B}$ ton $\mathrm{km} / \mathrm{yr}$ )

Based on converting US costs for Diesel Truck in LLEM to China's costs. 
Operating Cost: 8.7e5 yuan/ B ton km

Based on converting US costs for Diesel Truck in LLEM to China's costs.

Life: 25 yrs

Availability factor: 1.0

Minimum capacity factor: 0.7

\section{I-O coefficients:}

From petroleum market transportation: 0.0138

See Trans Sector CED 1996 file.

\section{Transportation sector highway passenger}

Output: B passenger km

Input: B passenger $\mathrm{km}$

Capacity: $276 \mathrm{~B}$ passenger $\mathrm{km} / \mathrm{yr}$

Capital and operating costs:

Capital Cost: $1.21 \mathrm{e} 9$ yuan/( B passenger km /yr)

Based on converting US costs for Gasoline Auto in LLEM to China's costs.

Operating Cost: 1 e8 yuan/ B passenger km

Based on converting US costs for Gasoline Auto in LLEM to China's costs.

Life: 25 yrs

Availability factor: 1.0

Minimum capacity factor: 0.7

\section{I-O coefficients:}

From petroleum market transportation: 0.04

From Data in LLEM and formula in appendix

\section{Domestic petroleum tax}

Output: Mtce

Input: Mtce

Capacity: 130 Mtce/yr 
Capital and operating costs:

Capital Cost: 0

Operating Cost: 0

Life: 5 yrs

Availability factor: 1.0

Minimum capacity factor: 0.5

I-O coefficients:

From domestic petroleum resource: 1

From domestic petroleum subsidy: -1

Imported petroleum tax

Output: Mtce

Input: Mtce

Capacity: 7 Mtce/yr

Capital and operating costs:

Capital Cost: 0

Operating Cost: 0

Life: 5 yrs

Availability factor: 1.0

Minimum capacity factor: 0.5

I-O coefficients:

From imported resource petroleum: 1.0

Constraints:

Max Quantity P: Constraint starts at 5.7 in 1988 (based on data).

Assume a constant growth rate of $10 \% / \mathrm{yr}$.

Residual petroleum tax

Output: Mtce

Input: Mtce

Capacity: $62 \mathrm{Mtce} / \mathrm{yr}$ 
Capital and operating costs:

Capital Cost: 0

Operating Cost: 0

Life: 5 yrs

Availability factor: 1.0

Minimum capacity factor: 0.5

I-O coefficients:

From residual resource petroleum : 1.0

Exact Quantity P:

Constraint set to 50 in all periods.

Petroleum refinery

Output: Mtce

Input: Mtce

From crude petroleum market and residual oil market:

Capacity: 133 Mtce/yr

Capital and operating costs:

Capital Cost: 483 yuan

Based on converting US costs for Petroleum Refinery in LLEM to China's costs.

Operating Cost: 80 yuan/yr

Based on converting US costs for Petroleum in LLEM to China's costs.

Life: 30 yrs

Availability factor: 0.95

Minimum capacity factor: .7

I-O coefficients:

From crude petroleum market: 1.05 
From residual oil market: -0.05

T II-15 of CED 96 suggests that residual products are a few percent of total output

\section{Petroleum distribution}

Output: Mtce

Input: Mtce

Capacity: 133 Mtce/yr

Capital and operating costs:

Capital Cost: 0

This node can be used to adjust petroleum product prices for distribution costs. In the initial version these are set to 0 .

Operating Cost: 0

Life: 50 yrs

Availability factor: 1.0

Minimum capacity factor: 0.5

\section{I-O coefficients:}

From refinery petroleum 1.0

Petroleum tax

Output: Mtce

Input: Mtce

Capacity: $110 \mathrm{Mtce} / \mathrm{yr}$

Capital and operating costs:

Capital Cost: 0 yuan/ (tce/yr)

Operating Cost: 300 yuan/tce

Life: 5 yrs

Availability factor: 1

Minimum capacity factor: 0.5

\section{I-O coefficients:}

From crude petroleum distribution: 1 
From $\mathrm{CO} 2$ emissions market: 0.563

Edmonds and Reilly (1985) (T 16-1, p243) show $19.2 \mathrm{gm} \mathrm{C/MJ}$ of energy. This converts to 0.563 tons carbon per tce.

\section{National Distribution Gas}

Output: Mtce

Input: Mtce

Capacity: 203 Mtce/yr

Capital and operating cost:

Capital Cost: 0

Operating Cost: 0

Life: 5 yrs

Availability factor: 1.0

Minimum capacity factor: 0.5

I-0 coefficients:

From market gas: 1.0

Gas tax

Output: Mtce

Input: Mtce

Capacity: 13 Mtce/yr

Capital and operating costs:

Capital Cost: 0 yuan

Operating Cost: 0 yuan/yr

Life: 5 yrs

Availability factor: 1

Minimum capacity factor: 0.5

I-O coefficients:

From gas market 1: 1 
From $\mathrm{CO} 2$ emissions market: 0.402

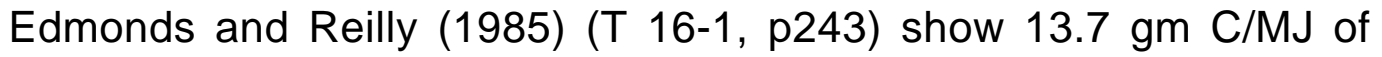
energy. This converts to 0.402 tons carbon per tce.

From sulfur emissions market : 0.004

\section{Gasification coal}

Output: Mtce

Input: Mtce

Capacity: 1 Mtce/yr

Capital and operating costs:

Capital Cost: 3135 yuan/ (tce/yr)

Based on converting US costs for Lurgi Gasification in LLEM to China's costs.

Operating Cost: 262 yuan/tce

Based on converting US costs for Lurgi Gasification in LLEM to China's costs.

Life: 30 yrs

Availability factor: 0.9

Minimum capacity factor: 0.5

\section{I-O coefficients:}

From coal market: 1.75

Based on converting US costs for Lurgi Gasification in LLEM to China's costs.

Coke coal

Output: Mtce

Input: Mtce

Capacity: $68 \mathrm{Mtce} / \mathrm{yr}$

Capital and operating costs:

Capital Cost: 500 yuan/ (tce/yr)

Based on analogous process(es) in LLEM90. 
Operating Cost: 50 yuan/tce

Based on analogous process(es) in LLEM90.

Life: 30 yrs

Availability factor: 0.9

Minimum capacity factor: 0.5

I-O coefficients:

From coal market 1.5

\section{Liquifaction coal}

Output: Mtce

Input: Mtce

Capacity: 2 Mtce/yr

Capital and operating costs:

Capital Cost: 5147 yuan/ (tce/yr)

Operating Cost: 525 yuan/tce

Based on converting US costs for Syncrude in LLEM to China's costs.

Life: 30 yrs

Availability factor: 0.95

Minimum capacity factor: 0.5

\section{I-O coefficients:}

From coal market: 1.75

Coal tax

Output: Mtce

Input: Mtce

Capacity: 700 Mtce/yr

Capital and operating costs:

Capital Cost: 0 yuan

Operating Cost: 200 yuan/yr

Life: 25 yrs 


\section{Availability factor: 1}

\section{Minimum capacity factor: 0.5}

\section{I-O coefficients:}

From domestic coal resource: 1

From CO2 emissions market: 0.698

Edmonds and Reilly (1985) (T 16-1, p243) show $23.8 \mathrm{gm} \mathrm{C/MJ}$ of energy. This converts to 0.698 tons carbon per tce.

\section{Biomass tax}

Output: Mtce

Input: Mtce

Capacity: 275 Mtce/yr

Capital and operating costs:

Capital Cost: 0 yuan

Operating Cost: 0 yuan/yr

Life: 5 yrs

Availability factor: 1

Minimum capacity factor: 0.5

\section{I-O coefficients:}

From biomass resource: 1

From $\mathrm{CO} 2$ emissions market: 0

From sulfur emission market 0.0

\section{Constraints}

Max Quantity P: In each period the constraint is set to 263 Mtce. This is the total biomass consumption by rural households for 1990 from TIV-21 CED96. It is not clear whether this could be expected to increase or decrease over time.

\section{Electric accumulator}

This node divides the total electric energy demanded into three load factors.

Output: Mtce electricity 
Input: Mtce electricity

Fraction 1: 0.6

Load factor 1: 1

Fraction 2: 0.35

Load factor 2: .4

Fraction 3: 0.05

Load factor 3: 0.1

\section{Electric distribution}

Represents the average losses and costs of electric transmission and distribution

Output: Mtce electricity

Input: Mtce electricity

Capacity: 74 Mtce/yr

Capital and operating costs:

Capital Cost: 0 yuan/ (tce/yr)

Operating Cost: 0 yuan/tce

Life: 25 yrs

Availability factor: 1

Minimum capacity factor: 0.5

\section{I-O coefficients:}

From accumulator electric: 1.08

Assume that overall the transmission and distribution system is about $70 \%$ efficient. Based on total end use of 533.6 Twh and a net generation of 578.4 Twh.

\section{Oil Combined Cycle Elect}

Represents an oil-fired combined cycle generator

Output: Mtce electricity

Input: Mtce refined petroleum

Capacity: 
Load Factor 1: 0.05

Load Factor 2: 0.02

Load Factor 3: 18.0

\section{Capital and operating costs:}

Capital Cost: 3,443 Y /(tce/yr).

Atwood (11Apr97) for $500 \mathrm{MW}$ units (this is equivalent to $\$ 500 / \mathrm{kw}$ at $8.4 \mathrm{Y} / \$)$

Operating Cost: 160 yuan/tce.

This technology is similar to the Combustion turbine/combined cycle (distillate fuel) technology in EPRI TAG (1989) (p 7-27). Since the capital costs for China are roughly half the capital costs in the US, we assume that the operating costs are roughly half. Use $50 \%$ of the operating cost given in TAG.

Life: 30 yrs typical value in TAG

Availability factor: 0.91

Value from EPRI TAG (1989) p 7-61 for combustion turbine combined cycle, distillate fuel

Minimum capacity factor: 0.4

\section{I-O coefficients:}

Product Market Petrol: 2.0

Based on 50\% efficiency from Atwood (11Apr97)

\section{Coal Domestic Technology Elect}

This represents a composite of the smaller $(<100 \mathrm{MW})$ and Larger (>300 mw) Chinese technology coal plants given by Atwood (11Apr97).

This node does not include flue gas desulfurization (FGD), but does include electrostatic precipitators (ESP). This node represents the existing capacity plus new capacity added from domestic sources

Output: Mtce electricity

Input: Mtce coal

Capacity:

Load Factor 1: 30

Load Factor 2: 55, 
Load Factor 3: 10

Capital and operating costs:

Capital Cost: $4,131 \mathrm{Y} /(\mathrm{tce} / \mathrm{yr})$

From Atwood (11Apr97) for "Chinese technology coal plants $>300 \mathrm{MW}$ with ESP". This corresponds to $\$ 600 / \mathrm{kw}$ at an exchange rate of 8.4 $\mathrm{Y} / \$$.

Operating Cost: Y 276/tce

This technology is similar to Pulverized Coal Technology in EPRI TAG (1989) ( $p$ 7-15). Assume that Chinese operating costs are on the order of $50 \%$ of US operating costs, since Chinese capital costs are on the order of $50 \%$ of US capital costs.

Life: 30 yrs

Availability factor: 0.7 , this is on the low side of availability factors reported in EPRI TAG (1989)

Minimum capacity factor: 0.4

\section{I-O coefficients:}

Coal market: 3.33

Atwood (11Apr97)shows $27 \%$ efficiency for smaller units and $33 \%$ for larger units. Use an intermediate value.

Sulfur emissions market: 0.037 (see Note 1)

\section{Coal Domestic Technology with FGD Elect}

Domestic technology for coal boiler with ESP and FGD.

Output: Mtce electricity

Input: Mtce coal

\section{Capacity}

Load Factor 1: 1.0

Load Factor 2: 10

Load Factor 3: 0.00

\section{Capital and operating costs:}

Capital Cost: 6,149 Y(tce/yr).

From Atwood data 11Apr97 
Operating Cost: $355 \mathrm{Y} / \mathrm{tce}$

This is similar to Pulverized Coal Technology in TAG ( $p$ 7-15). Assume that Chinese operating costs are on the order of $50 \%$ of US operating costs, since Chinese capital costs are on the order of $50 \%$ of US capital costs.

Life: 30 yrs based on EPRI TAG (1989)

Availability factor: 0.7 , this is on the low side of availability factors reported in EPRI Tag (1989)

\section{Minimum capacity factor: 0.4}

\section{I-O coefficients:}

Coal market: 3.7

Efficiency without FGD is about 0.30 .

Assume that the FGD reduces efficiency to about 0.27 .

Sulfur emissions market: 0.0

\section{Coal Foreign Technology Elect}

Foreign conventional coal technology with ESP but no FGD

Output: Mtce electricity

Input: Mtce coal

\section{Capacity:}

Load Factor 1: 1.0

Load Factor 2: 3

Load Factor 3: 0.001

\section{Capital and operating costs:}

Capital Cost: 7,053/(tce/yr).

Atwood (11Apr97) gives range of $Y 7,053 \mathrm{Y}$ to $8,138 \mathrm{Y} /$ tce $(\$ 780 / \mathrm{kw}$ to $\$ 900$ at an exchange rate of $8.4 \mathrm{Y} / \$$.). Use low end of this range.

Operating Cost: $271 \mathrm{Y} /$ tce

See note for Coal Domestic Technology operating costs

Life: 30 yrs based on EPRI TAG (1989) 
Availability factor: 0.85

Value from EPRI TAG (1989) p 7-15 for conventional pulverized coal

Minimum capacity factor: 0.4

\section{I-O coefficients:}

Coal market: 2.63

Atwood shows maximum efficiency of 0.38 .

Assume that new units will achieve this maximum.

Sulfur emissions market: 0.029

Coal Fluidized Bed Elect

Output: Mtce electricity

Input: Mtce coal

Capacity:

Load Factor 1: 1

Load Factor 2: 3

Load Factor 3: 0.001

Capital and operating costs:

Capital Cost: 7,234 Y/(tce/yr).

From Atwood (11Apr97) (equivalent to $\$ 800 / \mathrm{kw}$ at $8.4 \mathrm{Y} / \$$ )

Operating Cost: $452 \mathrm{Y} / \mathrm{tce}$

This is similar to the Atmospheric Fluidized Bed technology in EPRI TAG (1989) ( $p$ 7-27). Since the capital costs for China are roughly half the capital costs in the US, we assume that the operating costs are roughly half. Use $50 \%$ of the operating cost given in TAG.

Life: 30 yrs based on TAG

Availability factor: 0.81

From EPRI Tag (1989) p 7-27 for atmospheric fluidized bed

\section{Minimum capacity factor: 0.4}

\section{I-O coefficients:}

Coal market: 2.56

Atwood (11Apr97) 
Sulfur emissions market: 0

Coal IGCC Elect

Integrated Gasification and Combined Cycle coal technology

Output: Mtce electricity

Input: Mtce coal

Capacity:

Load Factor 1: 1

Load Factor 2: 2.5

Load Factor 3: 0.001

Capital and operating costs:

Capital Cost: 7,686 Y/(tce/yr).

Atwood (11Apr97) (equivalent to $\$ 850 / \mathrm{kw}$ at $\$ 8.4 \mathrm{Y} / \$$ )

Operating Cost: 357 yuan/tce.

This is similar to the IGCC technology in EPRI TAG (1989), p7-41 Tech:

16.2; $400 \mathrm{MW}$ plant. Since the capital costs for China are roughly half the capital costs in the US, we assume that the operating costs are roughly half. Use $50 \%$ of the operating cost given in TAG.

Life: 30 yrs typical value from TAG

Availability factor: 0.85

From EPRI TAG (1989) p 7-41 for IGCC

Minimum capacity factor: 0.4

\section{I-O coefficients:}

From Coal market: 2.38 .

Atwood (11Apr97)

From Sulfur emissions market: 0

Electric sector nuclear boiler

Output: Mtce electric

Input: Mtce of heat energy from nuclear fuel

\section{Capacity:}

Load factor 1: 0.2

Load factor 2: 0.015 
Load factor 3: .0001

Capital and operating costs:

Capital Cost: 11,700 yuan/(tce/yr).

Sinton (July 1996) quotes a cost of 2,000/kWe ( $\mathrm{Y} / \mathrm{kWe}$ ). However, he states that this is expected to drop to $\$ 1,200 / \mathrm{kWe}$ by 2020 . Use an intermediate value of $\$ 1,500 / \mathrm{kWe}(\mathrm{Y} 11,700 /(\mathrm{tce} / \mathrm{yr}))$

Operating Cost: 468 yuan/tce.

EPRI TAG (1989) indicates that operating costs per unit output are on the order of $4 \%$ of capital costs per unit capacity

Life: 30 yrs

Availability factor: 0.70

this on the low side of what is given in EPRI TAG (about 80 to $85 \%$ )

Minimum capacity factor: 0.4

\section{I-O coefficients:}

Nuclear Tax: 3.33

Assume about $30 \%$ efficient

Constraint: MaxQuantityC constraint. The current existing capacity is about 2 GWe (CED (1996) T II-21, p II-70) with a total output in 1994 of 13.9 TWh. assume that output in first period for base load is 2 Mtce and is allowed to grow at about $10 \% / \mathrm{yr}$.

\section{Nuclear Tax}

Output: Mtce

Input: Mtce

Capacity: 2 Mtce/yr

Capital and operating costs:

Capital Cost: 0

Operating Cost: 0

Life: 5 yrs

Availability factor: 1

Minimum capacity factor: 0.5

\section{I-O coefficients:}


From Nuclear Resource Electric: 1.0

\section{Hydro Electric}

Output: Mtce

Input: Mtce

\section{Capacity:}

Load Factor 1: 25

Load Factor 2: 7

Load Factor 3: 3

\section{Capital and operating costs:}

Capital Cost: 6,500 yuan/(tce/yr)

From Sinton (July 1996). This is the value for large hydro plants

(equivalent to $Y 7,000 / \mathrm{kWe})$. Sinton gives $\mathrm{Y} 12,000 / \mathrm{kWe}(\mathrm{Y} 11,140$ $/($ tce/yr)) for small plants. We use the value for large plants on the assumption that most of future generation will come from large plants.

Operating Cost: 1.0 yuan/tce.

These are accounted for in the costs of the hydro resource. It is convenient to use this approach since the Tax Hydro node required a none zero input price in order to activate the constraints.

Life: 100 yrs

Availability factor: 0.45

IEA WEO (1994) (p 168) notes that the capacity factors of hydro are currently less than 0.40 due to the "variable flows of many small

plants". This is expected to increase to above 0.45 since many of the new plants will be on a larger scale than existing plants. Since the low capacity factor is due to river flows, we assume that this is equivalent to the availability factor for the hydro plants-although the plant may be operable a large fraction of the year, the flows are not high enough to produce at full capacity.

\section{Minimum capacity factor: 0.5}

\section{I-O coefficients:}

From tax hydro: 1.0 


\section{Hydro tax}

This node is provided as a mechanism to impose taxes or constraints on hydro.

\section{Output: Mtce}

\section{Input: Mtce}

Capacity: $15 \mathrm{Mtce} / \mathrm{yr}$

\section{Capital and operating costs:}

Capital Cost: None

Operating Cost: None

Life: 5 yrs

\section{Availability factor: 1.0}

The actual capacity factors of hydropower are less than 0.5. However, this will be accounted for in setting the constraints. See discussion below on constraints.

\section{Minimum capacity factor: 0.5}

\section{I-O coefficients:}

From Hydro Resource Electric 1.0

Constraint: Max Quantity C:

CED (1996) (T II-2, p II-16) shows 126.7 Twh of hydro electricity in 1990. This is equivalent to $126.7 \mathrm{Twh} / \mathrm{yr} * 0.122 \mathrm{Mtce} / \mathrm{TWh}=15.5$ $\mathrm{Mtce} / \mathrm{yr}$

IEA WEO (1994) (p 168) projects 70 GW capacity (75 Mtce/yr) by 2000 and 120 GW (129 Mtce) by 2010. In 1994 they report that hydro capacity was about $40 \mathrm{GW}$. At that time there were about $20 \mathrm{GW}$ under construction. The Three Gorges Dam would add an additional 17 GW by 2010 (if it stays on schedule). This would give a total capacity of about $77 \mathrm{GW}$ from these projects alone.

IEA WEO (1994) (p 168) notes that the capacity factors of hydro are currently less than 0.40 due to the "variable flows of many small plants". This is expected to increase to above 0.45 since many of the new plants will be on a larger scale than existing plants. We account for the capacity factor in the constraint on total hydro energy. We will assume a 0.45 capacity factor. We also assume that the low capacity 
is due in large part to the unavailability of water flows in part of the year, or the need to store water for other purposes.

For the near term: The total generation in 1990 was $15.5 \mathrm{Mtce} / \mathrm{yr}$. We assume that the total capacity will be $70 \mathrm{GW}$ in 2000 and $120 \mathrm{GW}$ in 2010. The actual generation will be 0.45 times this or $31.5 \mathrm{GW}$ (34 Mtce/yr) in 2000 and 54 GW (58 Mtce/yr) in 2010.

For the long term: Table I-4 of CED(1996) shows 1,923.3 TWh/yr of exploitable hydro resources, which is equivalent to $234 \mathrm{Mtce} / \mathrm{yr}$.

Assumed that half of this would be developed by the end of the model horizon or 117 Mtce/yr.

We assume linear growth between these given points.

\begin{tabular}{|l|c|c|c|c|c|c|c|c|c|c|}
\hline Period & 1 & 2 & 3 & 4 & 5 & 6 & 7 & 8 & 9 & 10 \\
\hline $\begin{array}{l}\text { maximum } \\
\text { generation } \\
\text { (MTCE/YR) }\end{array}$ & 15.5 & 23.0 & 32.0 & 45.0 & 58.0 & 69.8 & 81.6 & 93.4 & 105.2 & 117.0 \\
\hline
\end{tabular}

\section{Electric sector wind}

Output: Mtce electric

Input: Mtce

\section{Capacity:}

These values are set based on results from an initial run

Load factor 1: 8

Load factor 2: 1

Load factor 3: 0.001

\section{Capital and operating costs:}

Capital Cost: 3011 yuan/ (tce/yr)

Based on converting US costs for Wind Turbine in LLEM to China's costs.

Operating Cost: 343.5 yuan/tce

Based on converting US costs for Wind Turbine in LLEM to China's costs.

Life: 20 yrs

Availability factor: 0.95

Minimum capacity factor: 0.5 
I-O coefficients:

From Wind Tax: 1.0

Wind tax

Output: Mtce electric

Input: Mtce energy

Capacity: $8 \mathrm{Mtce} / \mathrm{yr}$

Capital and operating costs:

Capital Cost: 0

Operating Cost: 0

Life: 5 yrs

Availability factor: 1

Minimum capacity factor: 0.5

I-O coefficients:

From Wind Resource Electric: 1.0

The efficiency is accounted for in the cost.

Constraint: Max Quantity P: Constraint set to $5 \mathrm{Mtce}$ in all periods

Sulfur emissions tax

Output: Tons sulfur

Input: Tons sulfur

Capacity: 890

Capital and operating costs:

Capital Cost: 0

Operating Cost: 0

Life: 5 yrs

Availability factor: 1

Minimum capacity factor: 0.5

I-O coefficients:

From Sulfur Resource Emission: 1.0 
CO2 emissions tax

Output: Tons carbon

Input: Tons carbon

Capacity: 890 Mtce/yr

Capital and operating costs:

Capital Cost: 0

Operating Cost: 0

Life: 5 yrs

Availability factor: 1

Minimum capacity factor: 0.5

I-O coefficients:

From CO2 Resource Emission: 1.0

\section{Resources}

\section{Imported petroleum}

Want this to balance to 8.8 Mtce based on CED 1996ed, T VII-1, for 1990

Output: Mtce

Start price: 609 yuan/tce

Price growth rate: $0.02 / y r$

Domestic petroleum subsidy

This node can be used to apply a subsidy to domestic petroleum.

Output: Mtce

Price: 0 in all periods

Domestic petroleum resource

Based on attempting to meet production of 197.58 Mtce in 1990, CED 1996ed, T II-1

Output: Mtce 
Price 0: 996 yuan/tce

Price 1: 1494 yuan/tce

Commitments 1: 4682 Mtce

Price 2: 2988 yuan/tce

Commitments 2: 14000 Mtce

Initial production: 197 tce

Production to reserves ratio: 0.1

Discount rate: 0.1

\section{Residual petroleum resource}

This node provides a price for the ResidTaxPetrol. The ResidTaxPetrol then increases this price the balance the Resid Oil Mkt. Thus the exact price provided here is not critical, as long as it is below the price required to balance the market.

Output: Mtce

Start price: 450 yuan/tce

Price growth: $0.003 / y r$

\section{Imported gas resource}

Output: Mtce

Start price: 1200 yuan/tce

Price growth: $0.02 / \mathrm{yr}$

\section{Domestic gas resource}

David Fridley of LBNL indicates that a study he completed for the World Bank derived a total production cost of gas of around $Y$ 430/tcm. This is about Y330/tce. This was for Sichuan region. The study used Western accounting practices (accounted for dry holes). He states the actual sales prices in China depend on the customer. Fertilizer plants are charged Y280/tcm (Y215/tce), industry is charged $Y$ 300/tcm (Y231/ tce) and commercial customers are charge about $Y$ 520/tcm (Y 400/tce). 
Yang et al report prices of 220 to $240 \mathrm{Y} / \mathrm{tcm}$ from Sichuan and 130 to $330 \mathrm{Y} / \mathrm{tcm}$ in other parts of the country.

Output: Mtce

Price 0: 400 yuan/ tce

This is approximately the price charged to commercial customer

Price 1: 1000 yuan/ tce

Assume that the price will increase by a factor of three as we commit all the reserves

Commitments 1: 1,330 Mtce

Total reserves are estimated to be 10 trillion m3 (CED96, TI-1). This is equivalent to $1.33 \times 10^{9}$ tce or $1.33 \times 10^{3}$ Mtce

Price 2: 5000 yuan/ tce

Commitments 2: 3000 Mtce

Assume a high price if the currently known reserves are exceeded.

Initial production: $20 \mathrm{Mtce} / \mathrm{yr}$

CED96, T II-1 shows 20.35 Mtce in 1990.

Production to reserves ratio: 0.1 nominal value

Discount rate: 0.1

\section{Sulfur resource emissions}

Output: Tons sulfur

Start price: 0.0 yuan/ $\mathrm{t}$

Price growth: $0.02 / \mathrm{yr}$

CO2 resource emissions

Output: Tons carbon

Start price: 0.0 yuan/t

Price growth: $0.02 / \mathrm{yr}$

\section{Domestic coal resource}

Output: Mtce 
Price 0: 50 yuan/ tce

Typical mine-mouth prices in 1990 appear to be in this range. CED96 $T$ $\mathrm{VI}-1$ gives an average of $\mathrm{Y} 43.85 / \mathrm{t}, \mathrm{T}$ VI-2 gives $\mathrm{Y} 77.93 / \mathrm{t}$

Price 1: 150 yuan/ tce

Assume that the price would triple as we reach the and of the reserves

Commitments 1: 114,500 Mtce

Total coal reserves from CED 96 T I-3

Price 2: 450 yuan/ tce

Commitments 2: 300,000 Mtce

This provides a high price as the known reserves are exceeded.

Initial production: $700 \mathrm{Mtce} / \mathrm{yr}$

Match production of 771.4 Mtce in period 1 (1990) based on CED 1996 T II-1.

Resource life: 30

Discount rate: 0.1

\section{Biomass resource}

Attempt to match production of 266.03 Mtce in period 1 (1990) based on CED 1996ed, T IV-21.

Output: Mtce

Start price: 40 yuan/tce

Price growth: $0.02 / y r$

\section{Nuclear electric resource}

Output: Mtce

Start price: 130 yuan/tce

Price growth: $0.03 / y r$

\section{Hydro resource electric}

This node normally would represent the cost of water input to the hydro electric turbine. This cost is zero. However, for convenience we 
assign the operating cost of the hydro electric plant to this node. This is convenient since the Tax Hydro node is used to enforce the constraints on total hydro electricity. That node requires a non zero input price in order to implement the constrain.

Output: Mtce

Start price: 130 yuan/tce

This cost represent the operation and maintenance cost of the hydro electric turbines and other components. This value is based on the operating costs given in TAG (1989) for Pumped Hydro Energy Storage which gives an operating cost of $\$ 0.0038 / \mathrm{kWh}(260 \mathrm{Y} / \mathrm{tce})(\mathrm{p} \mathrm{7-113})$. Since this cost covers the cost of operating the pumps and the turbines (this does not cover the cost of energy required for pumps), we assume the cost of the turbines alone is in the order of a half this amount. This is in the same ballpark as operating costs for other types of generators.

Price growth: $0.0 \mathrm{yr}$

\section{Wind resource electric}

Output: Mtce

Start price: 500 yuan/tce

Price growth: $0.02 / y r$

\section{Appendix C: References for model parameters}

Atwood (11Apr97): Private communication from Ted Atwood, DOE, Office of Fossil Energy

CED 96: Sinton, Jonathan. Editor, China Energy Databook,. Lawrence Berkeley National Laboratory, LBL-32822, Rev. 4, UC-900, Revised September 1996

CLCE: Cost of Limiting CO2 Emissions: China Case Study by Shuyu Zhang, Jayant Sathaye (LBL Univ of Calif) and Zongxin Wu, Jiankun He (Institute of Nuclear Energy Technology, Tsinghua University) 1995 Draft.

Edmonds and Reilly: Edmonds, Jae and John M. Reilly, Global energy assessing the future, Oxford University Press, 1985 
Fridley: Fridley, David, Lawrence Berkeley National Laboratory, private communication

GRI: Gas Resource Institute, Cost and performance estimates for energy supply and utilization processes, GRI-85/0130, 1985

IEA WEO (1994): International Energy Agency, World energy outlook, 1994 edition, Organization for Economic Cooperation and Development, Paris, 1994

LLEM: Lawrence Laboratories Energy Model: Process Data Book unpublished data, Lawrence Livermore National Laboratory, 1990

Sinton: Sinton, Jonathan (July 1996) personal communications

Sinton, Jonathan A Review Of Power Plant Costs In China Lawrence Berkeley National Laboratory internal memo December 11, 1995

TAG (1989): TAG: Technology Assessment Guide Electric Power Research Institute, EPRI P-6587-L, Vol. 1: Rev. 6 Special Report, September 1989

Yang, F, N. Duan, Z. Huan, M. D. Levine, N. C. Martin, J. E. Sinton, Q. Wang, D. Zhou, and C. Zhu, A Review of China's Energy Policy LBL35336, UC-900, Dec. 1994

\section{Appendix D: Notes}

Note 1: Calculation of sulfur emissions I-O coefficient

The I-O coefficient for sulfur emissions depends on the sulfur content of the fuel and the process's I-O coefficient for fuel. The amount of sulfur emitted per unit of output is I-O for fuel times the sulfur content of fuel, expressed as a fraction.

Note 2: Freight Transportation Growth

Freight transport growth is assumed to grow at the same rate as the GNP. This rate is based on growth of $6 \%$ from $1990-2000,4.5 \%$ from 2000-2020, and 3.6\% from 2020-2050. Table 2.2 and 4.1 CLCE. In the last period, we used the slower growth assumption from table 2.2 for the prior period as an illustration. 


\section{Appendix E: Derivation of growth rates}

Industrial sector demand growth formula. From tables 2.2, 2.3, 4.1 in CLCE.

Table 2.2 lists average annual growth rate of GNP (\%) for the following periods $1990-2000$ (6\%), 2000-2020 (4.5\%). For period 2020-2050 we used the low growth scenario (3.6\%) from table 2.2 period $2000-2020$ as the more conservative scenario for periods beyond 2020.

GNP projections were based on table 4.1 scenario 1 year 19901700 billion yuan, year 20003045 billion yuan, year 20207340 billion yuan. For year 205021222 billion yuan was estimated (using the slower growth rate as mentioned above).

Percent of GNP by sector was taken from table 2.3

To estimate each sector's growth rate the following formulas were used,

Sector percent of GNP * GNP for period $1=\mathrm{X}$

Sector percent of GNP * GNP for period $2=\mathrm{Y}$

$\mathrm{Y} / \mathrm{X}=\mathrm{Z}$ (percent change from period 1 to 2 ).

$Z^{*} \log$ (number of years between the two periods)= annual percent growth

Agricultural sector demand growth formulas

Output grows at $2.7 \%$ based on above formulas. In 30 years output grows to $(1.027)^{30} .=2.224$

1990 Mechanization $=.30$

2020 Estimated Mechanization $=.60$ 
Growth Rate $=\mathrm{x}$

$.30(1+x)^{30}=.60 * 2.224$

$x=0.051$

Residential sector urban heating and cooking demand growth formulas

Output grows at $3.9 \%$ over 60 years based on above formulas.

1990 urban population $=.26$ page 5 CLCE

2050 urban population $=.60$ page 5 CLCE

Growth Rate $=x$

$.26(1+x)^{60}=.60 * 9.93$

$x=0.54$

Residential sector rural heating and cooking demand growth formulas

Output grows at $3.9 \%$ over 60 years based on above formulas.

1990 rural population $=.736$ Table 2.1 CLCE

2050 rural population $=.40$ page 5 CLCE

Growth Rate $=\mathrm{x}$

$.736(1+x)^{60}=.40 * 9.93$

$\mathrm{X}=0.028$

Transportation Sector

LLEM gives capital and operating cost in thousand-ton miles. We convert this to billion-ton $\mathrm{km}$. We also convert it to Yuan and estimate a 50\% lower capital and operating cost over US costs.

1 thousand-ton miles $/ 1.6^{*} 10^{\wedge} 6=$ billion-ton $\mathrm{km}$

Dollars to Yuan $1 * 7.2$

Lower Chinese capital and operating cost factor

$* 0.5$ 
Converting US Efficiency to I-O Coefficient for China

$1 \mathrm{Btu}=36.0^{*} 10^{\wedge}-9 \mathrm{tce}$

(Btu/ton-mile) ${ }^{*} 1000=1000$ btus $/ 1000$ ton-mile* $\left(36.0^{*} 10^{\wedge}-9\right.$ tce $/ 1$

$\mathrm{Btu}){ }^{*}(1 \mathrm{mile} / 1.6 \mathrm{~km})=\mathrm{tce} / 1000$ ton $-\mathrm{km}{ }^{*} 10^{\wedge} 6=\mathrm{mtce} / \mathrm{billion}-$ ton $\mathrm{km}$

Passenger Transportation

Assume 2.3 passengers per vehicle LLEM

(Thousand passenger miles/MBTUs) ${ }^{\wedge}-1=$ MBTUs/thousand passenger miles

(MBTUs/thousand passenger miles * $\left.36{ }^{*} 10^{\wedge}-3 \mathrm{MTCE} / \mathrm{MBTUs}\right) / 1.6 \mathrm{~km}$ $=$ billion passenger miles/MBTUs 